\title{
Variable Demand Elasticities and Tariff Liberalization
}

\author{
Alan C. Spearot* \\ University of California - Santa Cruz
}

May 17, 2012

\begin{abstract}
This paper examines tariff liberalization within an environment of heterogeneous demand elasticities. Varieties produced at a lower cost (a) are imported at lower absolute demand elasticities and (b) earn higher revenues. By virtue of larger demand elasticities, low revenue varieties benefit the most from tariff liberalization. Further, if varieties are substitutable, low revenue varieties benefit at the expense of high revenue varieties. These predictions are confirmed using a case study of US Uruguay Round ad-valorem tariff cuts, where within exporter-industry groups, low revenue varieties experienced large gains, and high revenue varieties experienced negligible gains. Further, I find evidence suggesting that these effects were also relevant for other trade shocks, such as exchange rates and specific tariffs.
\end{abstract}

JEL Classifications: F12, F13, F14

Keywords: Firm Heterogeneity, Variable Elasticities, Trade Liberalization, Non-discrimination

\footnotetext{
*Email: acspearot@gmail.com. Address: Economics Department, 1156 High Street, Santa Cruz, CA, 95064. I thank Pol Antràs and two annonymous referees for helpful comments and suggestions. I also thank David Hummels, Wolfgang Keller, Dirk Krueger, Volodymyr Lugovskyy, Phillip McCalman, Peter Morrow, Thanh Xuan Nguyen, Anson Soderbery, Robert Staiger and seminar participants at the 2009 Otago Workshop on International Trade, the London School of Economics, the 2009 Asia Pacific Economics Association Annual Conference, the 2009 Empirical Investigations in Trade and Geography conference, the University of Colorado, the Stanford Institute for Theoretical Economics, and the University of Michigan for very helpful comments and discussions. Finally, I thank James Allen from the New Zealand Ministry of Foreign Affairs and Trade for HS8 trade data used for an earlier working paper. All remaining errors are my own.
} 


\section{Introduction}

If one point has been made abundantly clear by the recent theory of international trade, it is that firms and firm heterogeneity have a profound effect on trade patterns. However, despite the significant amount of heterogeneity in firms and varieties across trading partners within narrowly defined products, the rules of the GATT/WTO, on a basic level, seem designed for a more homogenous environment. With regard to tariffs, this point is particularly salient, as outside of special safeguards, retaliatory measures, and all-or-nothing regional agreements, members have very little latitude regarding tariffs applied to different varieties of the same product. One particular guiding principle, "non-discrimination", imposes that all GATT/WTO members receive equal treatment, usually via a common, or "most favored nation" (MFN), tariff. This applies within any product, across all export sources without preferential status, and (obviously) does not discriminate by product characteristics. Further, this equal treatment rule extends to the process of liberalization, and allows for no consideration of which exporters and/or varieties stand to gain more or less from lower tariffs.

As an example, consider imports within the largest passenger vehicle category (HS8 code 87032300 ) by the United States in 1992. Overall, the US imported varieties within this product category from 13 different countries at an average pre-tariff unit-value of $\$ 15,315.67$. However, this average varied substantially by country. For example, while the average import from Japan was fairly low price $(\$ 8,112.04)$, the average imported vehicle from Germany was substantially more expensive $(\$ 25,475.98)$. Hence, it is unlikely that the average variety from each exporter has the same characteristics. Further, looking within imports from Germany across eleven HS10 sub-categories, the average price ranged from $\$ 9,000$ to $\$ 44,000$. Hence, not only are imports from Germany and Japan quite different, but within Germany, imports across HS10 categories are also quite differ-

ent. Yet, the WTO mandates that these products are treated equally in setting tariffs, and when liberalizing tariffs.

Overall, there is a clear friction between the precise intent of WTO rules regarding tariffs, and the natural differentiation which occurs in trade flows. Critically, even though the WTO prefers (and arguably promotes) the multilateral process over other preferential or regional schemes, it remains unclear how the effects of MFN liberalization accrue within products that exhibit significant differentiation in varieties. In what way should MFN tariff reductions influence bilateral trade flows? Are certain varieties more likely to gain from MFN liberalization based on their fundamental demand characteristics? Overall, how are the benefits of additional import market access distributed across competing and differentiated export suppliers?

This paper answers these questions. Using a simple theoretical model based on Melitz and 
Ottaviano (2008), I show that the liberalization of a common ad-valorem tariff need not increase bilateral imports of all varieties. In particular, if elasticities vary across varieties, I show that liberalization of a common tariff has a natural disparate effect on the composition of aggregate trade flows. Indeed, within a wide class of demand systems that are consistent with empirical evidence in Campbell and Hopenhayn (2005), Foster, Haltiwanger, and Syverson (2008), and more recently Feenstra and Weinstein (2010), the liberalization of a common tariff disproportionately increases imports of low revenue varieties, and in some cases, this increase comes at the expense of high revenue varieties. In analyzing the effects of US Uruguay Round tariff cuts, I find robust support for the model. Specifically, using within-exporter-industry variation in import values, I find that tariff elasticities are large, negative, and statistically significant for low revenue varieties and smaller and not statistically different from zero for high revenue varieties. In some cases, imports of high revenue varieties fall after tariff liberalization.

The key to the model is the degree to which demand elasticities vary across varieties. First, consider low-cost varieties, which earn relatively large revenues, and for a wide class of demand systems are also sold at relatively low absolute demand elasticities. ${ }^{1}$ Given the low demand elasticities for these varieties, changes to tariffs have a fairly small direct effect on the value of bilateral imports. This is in stark contrast with varieties produced at a high cost, where revenues are fairly small but equilibrium demand elasticities are relatively large. Hence, for these varieties, changes to tariffs have a relatively large effect on the value of bilateral imports.

In equilibrium, the effects of changes to a common tariff are aggregated across all varieties, and competition is generally tougher when tariffs fall. That is, when tariffs fall, so does the residual demand for each variety, all else equal. It is the resolution of the tension between this aggregate effect and the effects related to demand elasticities which determine the varieties that benefit from tariff liberalization and to what extent. In particular, I show that the aggregate effect may in fact be larger than the direct effect for some varieties. As detailed above, these are the varieties that earn relatively large revenues before tariffs are cut. Thus, as a novel result, I show that tariff liberalization may in fact decrease imports of varieties that earn large revenues before the tariff cut. In contrast, I show that varieties earning low revenues always benefit from tariff liberalization by virtue of the high demand elasticity at which these varieties are sold. Overall, I show that for a wide class of demand systems, the traditional negative effects of tariffs are amplified for low revenue varieties, and smaller and/or of opposite sign for high revenue varieties.

Empirically, the model is evaluated using a case study of tariff reductions by the United States

\footnotetext{
${ }^{1}$ This is in contrast with the CES demand curve, where elasticities do not change with quantity. This results from the elasticity of the marginal revenue curve, which for CES is constant in quantity.
} 
resulting from Uruguay Round GATT negotiations. Despite being a result of bargaining within the GATT, this case study is sensible on a number of levels. For one, data are available at the ExporterHS10 level, which provides a useful amount of detail within narrowly defined products. ${ }^{2}$ Second, reductions to MFN tariffs were relatively quick, most of which occurring over the period 19951999. Third, the evidence suggests that import growth rates before the Uruguay Round agreements were drafted were independent from whether or not an HS8 product received a tariff cut after the Uruguay Round was completed. Finally, the US HS8 tariff data provides information on whether specific tariffs were present, which provides for an analysis of multiple policy instruments.

Overall, I find evidence which is broadly supportive of the model. Regressing bilateral import growth rates on tariff growth rates and an interaction with initial import values, I find that within exporter-industry pairs, bilateral import elasticities (with respect to tariffs) were large, significant, and negative for varieties with the smallest pre-Uruguay Round import values. In contrast, and consistent with the theory, estimated elasticities are small and, with few exceptions, not significantly different from zero for varieties with the largest pre-Uruguay Round import values. In some cases, the point estimates are greater than zero, which is a novel focus of the theoretical models in Sections 2 and 3. These results are sharpened when focusing on products that exhibit higher within-industry substitution (as in Broda and Weinstein (2006)), as the theory predicts. Further, the results suggest that there is a substantial bias in naively assuming that elasticities are invariant to pre-liberalization import values. Precisely, the average true elasticity at the exporter-industry level is roughly one point less elastic than the naively estimated constant elasticity. Relative to the typical constant elasticity of bilateral imports (roughly -2), this bias is substantial. Finally, I evaluate additional policy measures and trade shocks, such as specific tariffs and exchange rates. While these trade shocks tend to be less pronounced over my sample period (especially specific tariffs), both affect trade flows in a manner consistent with the theory.

\section{Related literature}

This paper adds to a number of different areas related to trade, firm heterogeneity, and trade policy. Most notably, it is related to the literature on the role of firm and variety heterogeneity in trade flows. ${ }^{3}$ The rather robust response of low revenue varieties is similar to Kehoe and Ruhl (2009), though documented at a more detailed level. Indeed, motivated in-part by these results,

\footnotetext{
${ }^{2}$ For example, "Grand Pianos" is an HS8 product, and HS10 provides detail such as "Containing a case measuring less than $152.40 \mathrm{~cm}$ in length".

${ }^{3}$ For example, Hummels and Skiba (2004), Helpman, Melitz, and Rubinstein (2008), Manova (2008), Hallak and Sivadasan (2009), Baldwin and Harrigan (2011), and Johnson (2011).
} 
Arkolakis (2010) presents a framework based on endogenous marketing costs that generates a larger response to trade liberalization by low revenue varieties. While similar to the results in my paper, the results are driven by a completely different mechanism. Further, there is one crucial qualitative difference in equilibrium predictions, where the Arkolakis framework guarantees that all firms gain from liberalization, which is not the case in my paper. ${ }^{4}$ Indeed, in the forthcoming empirical work, imports from the top 10\% of Exporter-HS10 pairs rarely increase after tariff liberalization occurs, and in certain industries, imports tend to fall for these successful varieties.

In allowing for an active extensive margin of trade, this paper is related to Helpman, Melitz, and Rubinstein (2008), Manova (2008), and Johnson (2011). Unlike these papers, I do not precisely adjust for sample selection of Exporter-HS10 observations given that good instruments are not available at this level of refinement. To this end, my paper is similar to Trefler (2004) in that I evaluate the impact of tariff liberalization on import growth within the set of continuing imported varieties. However, I provide a robustness check using an alternate specification that suggests that sample selection is not driving the differential response of tariffs by initial market penetration.

In aggregating firm-level trade to exporter-level trade within each industry, I draw from the recent literature on multi-product firms in Bernard, Redding, and Schott (2011) and Mayer, Melitz, and Ottaviano (2011). However, the relationship to these papers is limited to the assumption that firms enter industries and not varieties, which motivates the appropriate use of fixed effects in the empirical specification. My work also extends the trade literature on variable-elasticity demand systems. In particular, the paper is related to Feenstra and Weinstein (2010), which adapts the methods from Feenstra (1994) to estimate the gains from trade using a non-CES (translog) demand system. Their estimates imply pricing/mark-up behavior which is consistent with Melitz and Ottaviano (2008) - the model at the heart of my paper.

There is a relatively recent literature examining the design of the WTO within the context of heterogeneous countries and products. Saggi (2004) compares optimal tariffs set on an MFN basis with those set via unconstrained discrimination in a n-country oligopoly model with heterogeneous suppliers. Generally, Saggi's model suggests that MFN tariff-setting benefits low cost suppliers since the optimal tariffs applied to their exports would be lower. However, the model does not examine the removal of tariffs on an MFN basis, and the corresponding effects on trade, which is the focus of my work. ${ }^{5}$ Ludema and Mayda (2009) examine the relationship between exporter concentration

\footnotetext{
${ }^{4}$ Via a CES demand assumption, all firms in the Arkolakis (2010) framework receive the same percentage demand shock resulting from tariffs. Thus, all firms gain from a reduction in a common iceberg transport cost, but differ in their supply response based on the marginal cost of reaching a larger fraction of consumers.

${ }^{5}$ In later work, Saggi and Sara (2008) uses a two country model to examine the National Treatment clause when products may differ in quality. A similar result is reached as in Saggi (2004), where a national treatment clause tends
} 
and observed tariff concessions by the US. In particular, they show that the US offered larger tariff concessions in products with a more concentrated group of export sources.

On broader level, my paper is related to the work of Rose (2004) and Subramanian and Wei (2007), who estimate the effects of GATT/WTO membership on bilateral trade flows using a standard gravity model. Critically, my model suggests that this particular class of empirical studies is misspecified by failing to allow for differential effects of GATT/WTO membership as a function of pre-GATT/WTO market penetration. Indeed, I show that there is a significant level of bias when assuming that tariff elasticities are constant across all suppliers within an industry. In this way, the results detailed below motivate modifications of the standard Anderson and Van Wincoop (2003) gravity model to allow for non-constant elasticities.

To begin the analysis of tariff liberalization, in Section 2, I focus on a single import market being served by a fixed group of exporting firms. In the Section 3, I extend the analysis to include multiple exporters, and heterogeneous firms within each exporter. Further, in Section 3, I aggregate trade to the exporter-product level, and outline an empirical strategy to test for elasticity differences when using data aggregated above the firm-level. In Section 4, I implement the empirical strategy from Section 3 using a case study of US tariff cuts during the Uruguay Round.

\section{Trade Liberalization and Firm Heterogeneity}

\section{Consumers}

The key to the model is the way in which consumers in the import market value product variety. As in Melitz and Ottaviano (2008), I assume that consumer preferences in the import market are quasi-linear, non-homothetic, and exhibit love-of-variety within a differentiated sector. Preferences of this type can be defined as follows:

$$
U=x_{0}+\theta \int_{i \in \Omega} q_{i} d i-\frac{1}{2} \eta\left(\int_{i \in \Omega} q_{i} d i\right)^{2}-\frac{1}{2} \gamma \int_{i \in \Omega}\left(q_{i}\right)^{2} d i
$$

Here, $\Omega$ is the measure of available differentiated varieties, and $q_{i}$ is consumption of variety $i$. Further, $x_{0}$ is the numeraire good, where $\theta(>0)$ and $\eta(>0)$ determine the substitution pattern between the differentiated industry and the numeraire. Finally, $\gamma(>0)$ represents the degree to which consumers value product variety within the differentiated sector.

to help those exporters selling the most competitive goods (highest quality goods). 
The budget constraint faced by consumers is written as,

$$
x_{0}+\int_{i \in \Omega} p_{i}^{c} q_{i} d i \leq I
$$

where $I$ is income of the representative consumer, and $p_{i}^{c}$ is the price at which consumers purchase varieties. Solving the maximization problem of the representative consumer, and assuming that there are $L$ such consumers, yields the following inverse demand function for each variety:

$$
p_{i}^{c}=\underbrace{\theta-\eta \int_{i \in \Omega} q_{i} d i}_{A}-\frac{\gamma}{L} q_{i} .
$$

In (2), $A$ is the demand intercept for each variety, and within $A, \int_{i \in \Omega} q_{i} d i$ is total production for the differentiated market. All else equal, the market is more competitive ( $A$ falls) if the consumption of all varieties is larger. Firms take $A$ as given when making decisions. Finally, when there are more consumers ( $L$ rises), the aggregate inverse demand curve is more flat and elasticities at any unit of production are larger.

\section{Firms}

For this section, assume that each supplier $i$ produces only one variety, where the variety produced by $i$ is done so at a constant marginal cost, $c_{i}$. For simplicity, I assume away the extensive margin of trade and the domestic sector for the moment, focusing instead on a fixed measure of imported foreign varieties, $N$. Short and long-run versions of this model with a domestic sector, multiple exporters, and free-entry will be detailed in the next section.

To sell a variety in the import market, the export supplier is required to pay an ad-valorem tariff $\tau$ on the value of each unit sold, and hence, the relationship between the consumer price detailed above and the price that producers receive is $p_{i}^{c}=(1+\tau) p_{i}^{s}$. This yields the following inverse demand function that foreign suppliers use to optimally set production for the import market:

$$
p_{i}^{s}=\frac{1}{t}\left(A-\frac{\gamma}{L} q_{i}\right)
$$

Here, $t=(1+\tau)$. Suppliers choose quantities to maximize profits, where the maximization problem is written as:

$$
\pi\left(c_{i}\right)=\max _{q_{i}}\left\{\frac{1}{t}\left(A-\frac{\gamma}{L} q_{i}\right) \cdot q_{i}-c_{i} q_{i}\right\}
$$


Solving the maximization problem, optimal production is written as

$$
q\left(c_{i}\right)=\frac{L}{2 \gamma}\left(A-c_{i} t\right) .
$$

Exports to the import market are positive if $c_{i}<\frac{A}{t}$. I adopt this assumption for all varieties for the remainder of this section, though I will allow for an active extensive margin in the next section.

The pre-tariff value of imports of variety $i$ is written as:

$$
v\left(c_{i}\right)=\frac{L}{4 \gamma t}\left(A^{2}-\left(c_{i} t\right)^{2}\right) .
$$

As trade data reports the value of imports before duties are assessed, and not the profits of each supplier, equation (4) is the object of interest. The value of imports will be affected by ad-valorem tariffs through two channels. The first is directly via the negative effect of tariffs on variety-specific revenue. There are also indirect effects of tariffs through the competitiveness term, $A$. Defining $\bar{c}$ as the average cost of imported varieties, and solving for $A$, we have,

$$
A=\left(\frac{2 \gamma}{2 \gamma+\eta N}\right) \theta+\left(\frac{\eta N}{2 \gamma+\eta N}\right) \bar{c} t .
$$

Intuitively, higher tariffs decrease production for the import market, thus making the market less competitive. This yields a higher residual demand for each variety, $A$. A useful way to characterize this result is the elasticity of $A$ with respect to $t$ :

$$
\epsilon_{A, t} \equiv \frac{\partial A}{\partial t} \frac{t}{A} \equiv \frac{\bar{c} t}{\frac{2 \gamma \theta}{\eta N}+\bar{c} t} \in(0,1) .
$$

While $A$ is clearly increasing in $t$, on a percentage basis, $A$ increases slower than $t$. Further, $\epsilon_{A, t}$ is increasing in $N$ and $\eta$, and falling in $\gamma$. Respectively, these imply that in more competitive markets (higher $N$ ), in which there is a larger degree of substitution between the differentiated sector and the numeraire (higher $\eta$ ), and a larger degree of substitution within the differentiated sector (lower $\gamma$ ), the response of $A$ is stronger relative to a change in $t$.

\section{Tariff Liberalization}

To study the two channels through which tariffs affect import value, I first log differentiate (4) with respect to $A$ and $t$, and exploit the (negative) monotone link between $c_{i}^{2}$ and $v\left(c_{i}\right)$ to solve for the 
elasticity of import value with respect to tariffs, $\epsilon_{v, t}$ :

$$
\epsilon_{v, t}=-\frac{A^{2} L \overbrace{\left(1-\epsilon_{A, t}\right)}^{>0}}{2 \gamma t v_{i}}+1 .
$$

In (7), the tariff elasticity is clearly not constant for all firms. The direct (negative) impact of higher tariffs will be more pronounced when the firm operates on a more elastic part of the demand curve. Within this model, low revenue varieties are consumed at a higher absolute elasticity of demand, and hence, experience a larger direct effect from higher tariffs. Along with the direct impact of tariffs, there are also equilibrium effects of tariffs through the demand level $A$, where with higher tariffs, competitiveness falls and $A$ rises. However, as long as $A$ does not rise on a percentage basis more than $t$, which is confirmed in (6), the response of imports to tariffs is more pronounced for smaller varieties. This result is summarized in Proposition 1.

Proposition 1 If $\epsilon_{A, t}<1$, the elasticity of trade value with respect to ad-valorem tariffs for a given variety $i$ is increasing in revenues $\left(v_{i}\right)$.

Proof. Immediate given the derivative of (7).

This result is not specific to linear demand, where within other common demand systems such as translog (Feenstra and Weinstein (2010)), ad-valorem tariffs have a larger direct effect on smaller varieties. $^{6}$ In the Appendix, I derive precisely the demand conditions under which this is the case. The key to the general results is the elasticity of the marginal revenue curve with respect to quantity, defined as $s(q)$, which is always negative when second order conditions are satisfied. First, I show that the elasticity of import quantity with respect to ad-valorem tariffs is negative, but more pronounced for small varieties if and only if $\frac{\partial s(q)}{\partial q}<0$. In terms of import value, given complex interactions between the aforementioned quantity elasticity and the relationship between mark-ups and quantities, the precise conditions are less sharp. ${ }^{7}$ However, an easily interpretable sufficient condition exists, where if the inverse elasticity of demand $(n(q))$ has very clear properties $\left(\frac{\partial n(q)}{\partial q}<0\right.$ and $\left.\frac{\partial^{2} n(q)}{\partial q^{2}} \leq 0\right)$, then the elasticity of import value with respect to ad-valorem tariffs is negative, but more pronounced for small varieties.

Interestingly, while Proposition 1 details how the import elasticity changes with import values, it does not say anything regarding the overall sign of the import elasticity. Indeed, it is possible

\footnotetext{
${ }^{6}$ Additional demand systems include those from Behrens and Murata (2011) and Rodríguez-López (2011).

${ }^{7}$ Specifically, the elasticity of import value with respect to tariffs is negative, but more pronounced for small varieties when $\frac{\partial s(q)}{\partial q}$ is sufficiently low (though not necessarily negative).
} 
that for some varieties the import enhancing direct effect of a tariff cut is outweighed by the import reducing effect of increased competitiveness. Intuitively, while any shift in $A$ is common for all varieties, the direct impact of $t$ is smaller when firms operate on a more inelastic part of the demand curve. Proposition 2 details exactly when, and for which varieties, the import enhancing direct effect of a tariff cut outweighs the import reducing effect of increased competitiveness.

Proposition 2 Tariff liberalization increases imports only if $v_{i}<\frac{A^{2} L\left(1-\epsilon_{A, t}\right)}{2 \gamma t}$. In equilibrium, tariff liberalization reduces imports of the largest varieties when $\bar{c} t>\frac{2 \gamma \theta}{\eta N}$.

Proof. The first statement is immediate from (7). The second statement is immediate when plugging-in $\epsilon_{A, t}$ to (7) and substituting the highest possible import value $v^{\max }=\frac{A^{2}}{4 \gamma t}$, for $v$.

In Proposition 2, it is possible for the value imports of the most successful varieties to fall when tariffs are cut. This is more likely to occur when love of variety $\gamma$ is small or $\eta$ is large. Intuitively, changes in competitiveness across imported varieties will have a larger effect on aggregate demand when varieties are more substitutable.

It is worth pointing out some caveats related to this result. Had we included a domestic sector, a larger domestic sector would have an opposite effect, tempering the effect of $t$ on $A$. Further, had we allowed for free entry it is possible that $\epsilon_{A, t}$ is very small or negative, and hence Proposition 2 may not apply. Using the extended model from the next section, the former is explicitly addressed in Appendix B, and the latter in both Appendix B and an online supplemental appendix.

As with Proposition 1, Proposition 2 is extended in Appendix A to a general demand function, where I show that if varieties are "strong" strategic substitutes in the sense that aggregate output has a strong negative effect on variety-specific inverse demand, then combined with the general requirements for Proposition 1, the total effects of liberalization are more negative for smaller varieties, and imports from the most successful export suppliers will fall after ad-valorem tariff liberalization.

In the forthcoming empirical work, along with the differential effect of ad-valorem tariffs described above, I will also focus on the qualitative direction of the tariff-response of high revenue varieties in order to examine whether variety-specific demand elasticities are empirically relevant in the way the model suggests. Indeed, this will help differentiate the model from other models that predict a differential effect (Arkolakis (2010), for example), but without the prediction that some import flows may fall after liberalization. However, before moving to the empirical work, I will evaluate how the predictions from the firm-level model apply to trade flows that are aggregated above the firm-level. 


\section{Trade Liberalization and Exporter Heterogeneity}

As trade data are rarely reported at the firm-level, I now develop a strategy to test for the relationship between demand elasticities and tariff liberalization when only more aggregate data are available. As in the previous section, I will focus on a single liberalizing import market, here labeled $H$, populated by $L_{H}$ consumers, where $M$ exporters (indexed by $l$ ) face a common ad-valorem tariff $t_{H}$ in serving market $H$. Further, to align with the later empirical case study, I will also allow for a specific tariff, $z_{H}$. With these two tariff measures, the relationship between consumer and producer prices is $p_{i}^{c}=t_{H} p_{i}^{s}+z_{H}$, and the pre-tariff value of trade to $H$ for any variety $i$ is written as:

$$
v\left(c_{i}\right)=\frac{L_{H}}{4 \gamma t_{H}}\left(\left(A_{H}-z_{H}\right)^{2}-\left(c_{i} t_{H}\right)^{2}\right)
$$

The effect of specific tariffs also depends on elasticities. While all varieties receive a uniform reduction in $z_{H}$, the percentage impact of this liberalization is larger for low $v\left(c_{i}\right)$ varieties. This response is general for a wider class of demand systems, though a more constrained set when compared to ad-valorem tariffs. ${ }^{8}$

I will now detail a strategy to test for a differential response of import values to tariffs based on elasticities when only more aggregate data are available. To focus the discussion, consider for the moment an arbitrary product group $s$ that is exported from country $l$ to the market in country $H$. An example of this in the trade data I will employ in the next section is an Exporter-HS10 group. Suppose further that within this product group there exists a measure of firms, $N_{l, s}$, that draw costs upon entry from a distribution characterized by the pdf $g_{l, s}(c)$ defined over the support $\left[0, c_{\text {max }}\right]$. Finally, assume that the upper bound of the distribution, $c_{\max }$, is non-binding, where $c_{\max }>\theta$.

A firm can profitably export to country $H$ if $c<\frac{A_{H}-z_{H}}{t_{H}}$. Aggregating imports to $H$ of product $s$ from exporter $l$, we have the following:

$$
\begin{aligned}
V_{l, s}^{H} & =N_{l, s} G_{l, s}\left(\left(A_{H}-z_{H}\right) / t_{H}\right) \bar{v}_{l, s}^{H} \\
& =N_{l, s} \int_{0}^{\frac{A_{H}-z_{H}}{{ }^{t} H}} v\left(c_{i}\right) g_{l, s}(c) d c
\end{aligned}
$$

Here, $\bar{v}_{l, s}^{H}$ is the average firm-level export from $l$ to $H$ in product $s$, and $G_{l, s}\left(\left(A_{H}-z_{H}\right) / t_{H}\right)$ is the fraction of entering firms that profitably export within this group. Derived in Appendix $\mathrm{B}, \frac{\partial V_{l, s}^{H}}{V_{l, s}^{H}}$ as

\footnotetext{
${ }^{8}$ The elasticity of quantity with respect to specific tariffs is negative but more pronounced for small varieties if $\frac{\partial s(q)}{\partial q}<-\frac{(s(q))^{2}}{q}$, where $s(q)$ is the elasticity of the marginal revenue curve with respect to quantity. For ad-valorem tariffs, this requirement was $\frac{\partial s(q)}{\partial q}<0$.
} 
a function of $\partial A_{H}, \frac{\partial t_{H}}{t_{H}}$ and $\partial z_{H}$ can be written as:

$$
\frac{\partial V_{l, s}^{H}}{V_{l, s}^{H}}=\frac{\partial N_{l, s}}{N_{l, s}}+\frac{\partial t_{H}}{t_{H}}+\frac{\left(A_{H}-z_{H}\right) L_{H}}{2 \gamma t_{H} \bar{v}_{l, s}^{H}}\left(\partial A_{H}-\partial z_{H}-\left(A_{H}-z_{H}\right) \frac{\partial t_{H}}{t_{H}}\right)
$$

In (10), after aggregating to the exporter-product level, the effects of trade shocks can be broken up into a number of components. The first is a simple change in the number of entrants within product $s$ in $l$, and the second a common (partial) effect of tariffs. The third term provides the link to the model developed in Section 2. While I will sharpen the third term in a moment $\left(\partial A_{H}\right.$ is a function of trade shocks in equilibrium), note that the basic intuition from Section 2 remains when aggregating to the exporter-product level. For example, consider the effects of ad-valorem tariffs, $t_{H}$. In (10), the negative effects of $t_{H}$ are large when $\bar{v}_{l, s}^{H}$ is relatively small - that is, when the average exporter sells on a relatively elastic portion of the demand curve.

\section{Empirical Implementation}

While the intuition related to average revenues and elasticities is straightforward, a difficulty arises when noting that the measure of entering firms, $N_{l, s}$, and average firm-level export revenues, $\bar{v}_{l, s}^{H}$, require information that is never reported in aggregate trade datasets. Further, while $\bar{v}_{l, s}^{H}$ is primarily a function of the average efficiency of exporters, $N_{l, s}$ may reflect the average efficiency of exporters along with country size, entry costs, and other issues specific to each exporter's market. Hence, it is important to abstract from changes to $N_{l, s}$ when testing for the differential effect of tariffs as a function of $\bar{v}_{l, s}^{H}$.

I now resolve these issues by putting more structure on the model in the spirit of the new literature on multi-product firms. Specifically, I now assume that the preferences of the differentiated industry described in (1) are split-up into a discrete set of products, $S$, where $\Omega$ (the set of active varieties) is now partitioned by these products. This distinction is important when considering the process by which firms enter to serve the differentiated industry. Indeed, I assume that within any country $j$ (including $H$ ), $N_{j}$ firms enter the differentiated industry, receiving a vector of cost draws across all products within the differentiated industry. As written above, firms operating in country $j$ draw from a continuous cost distribution $g_{j, s}(c)$, defined over $\left[0, c_{\text {max }}\right]$, for each product $s$. These distributions are assumed to be independent, but not identical. Hence, $s, l$ pairs differ within exporter $l$ according to the distribution governing costs. Finally, as in Bernard, Redding, and Schott (2011) and Mayer, Melitz, and Ottaviano (2011), I assume that there is no cannibalization across different products produced by the same firm. 
The motivation for setting up the entry process in this way is two-fold. First, by assuming that the entry process is at the industry level and not the product level, we now have that $N_{l, s}=N_{l}$ and $\frac{\partial N_{l, s}}{N_{l, s}}=\frac{\partial N_{l}}{N_{l}}$. Hence, using an exporter-industry fixed effect, the first term in (10) will be fully absorbed, leaving the remaining variation a function of industry-level trade shocks and variation in $\bar{v}_{l, s}^{H}$. Second, this approach facilitates a novel way to proxy for $\bar{v}_{l, s}^{H}$. Specifically, exporter-products with lower average costs will have a higher $\bar{v}_{l, s}^{H}$ and a larger share of exporting firms. Given a common measure of entering firms $\left(N_{l}\right)$, this implies a larger value of total revenues in selling to $H$, $V_{l, s}^{H}$. Thus, within exporter-industry groups, there is a positive and monotone relationship between $\bar{v}_{l, s}^{H}$ and $V_{l, s}^{H}$. Hence, when moving to the empirics, I will use $V_{l, s}^{H}$ as a reduced-form proxy for $\bar{v}_{l, s}^{H}$.

\section{Discussion}

One of the interesting features of the within-exporter-industry empirical strategy is that it requires multiple products within an exporter-industry to test the model, and across these products, variation in $\bar{v}_{l, s}^{H}$. In a subtle but important way, this highlights the extension of the model relative to Melitz and Ottaviano (2008), which does not allow for heterogeneity in $\bar{v}_{l, s}^{H}$. Indeed, in Melitz and Ottaviano (2008), the lack of heterogeneity in $\bar{v}_{l, s}^{H}$ is due to a common Pareto shape parameter across exporters, which within a given import market, yields identical exporter-size distributions. ${ }^{9}$ Hence, when going to the data using the within-exporter-industry empirical strategy, finding a differential effect of tariffs not only links to variable elasticities, but it also implies particular distributional assumptions across products within an exporter that yield these elasticity differences.

It is also worth comparing the specification in (10) to the modified gravity specifications from the literature on the extensive margin of trade. In particular, in Helpman, Melitz, and Rubinstein (2008), after taking logs of the bilateral import specification, one must control for sample selection of country pairs that do not trade with one another, and firm-level selection into export status. In (10), after log differentiating, the entire effect of the latter is absorbed into $\bar{v}_{l, s}^{H}$. In terms of the typical "Heckman" sample selection problem, the current model does not provide for any advantages. Unfortunately, given the disaggregate nature of the empirics (Exporter-HS10), proper exclusions are extremely hard to find. Hence, I will adopt an empirical approach which examines import growth for continuing varieties, which is similar to the long-run analysis of continuing firms in Trefler (2004). However, I will also offer a robustness check using an alternate measure of import growth which suggests that sample selection is not driving the results.

\footnotetext{
${ }^{9}$ For example, under Pareto with a shape parameter $k$, if the cost-cutoff for imports to $H$ is $\frac{A_{H}}{t_{H}}$, then $\bar{v}_{l, s}^{H}=$ $\frac{A_{H}^{2}}{2 \gamma t_{H}(k+2)}$. Hence, if assuming Pareto, variation in $k$ is necessary for variation in $\bar{v}_{l, s}^{H}$.
} 


\section{Short and Long Run Equilibria}

I now derive the effects of trade shocks on the residual demand level, $A_{H}$. In the short-run, $N_{j}$ is fixed in each country $j$, and $A_{H}$ is pinned down using (2):

$$
\begin{aligned}
A_{H} & =\theta-\eta Q_{H} \\
& =\theta-\eta \sum_{s \in S}\left(N_{H} \int_{0}^{A_{H}} \frac{A_{H}-c}{2 \gamma} g_{H, s}(c) d c+\sum_{l=1}^{M} N_{l} \int_{0}^{\frac{A_{H}-z_{H}}{t_{H}}} \frac{A_{H}-z_{H}-c \cdot t_{H}}{2 \gamma} g_{l, s}(c) d c\right)
\end{aligned}
$$

Here, $Q_{H}$ is total consumption of differentiated varieties by the representative consumer in $H$, which may include domestic or imported varieties.

In the long-run, $A_{H}$ is pinned down by the free entry conditions. For simplicity, I assume that trade is one way toward the liberalizing import market in $H$. Given this one-way structure of trade, assuming a fixed cost of entry $F_{E}$, the free entry condition in $H$ is written as:

$$
\sum_{s \in S}\left(L_{H} \int_{0}^{A_{H}} \frac{\left(A_{H}-c\right)^{2}}{4 \gamma} g_{H, s}(c) d c\right)=F_{E}
$$

Using the conditions for the short and long run equilibria, along with the relationship between $\bar{v}_{l, s}^{H}$ and $V_{l, s}^{H}$, in Appendix B, I prove the main Proposition of Section 3:

Proposition 3 Within the differentiated industry in exporter l, ad-valorem or specific tariff liberalization in $H$ increases imports to a larger degree for those products s earning the smallest revenues pre-liberalization.

Proof. See Appendix B.

The results for the short-run equilibria are analogous to Section 2. Holding the number of entrants fixed in each country, higher ad-valorem or specific tariffs decrease competitiveness, but never so much to overturn the average "traditional" effect of tariffs (ie. $\epsilon_{A, t} \in(0,1)$ ). In the longrun, given the one-way nature of trade, it is immediate that $A_{H}$ is pinned down by the free entry condition in $H$, within which tariff measures play no (direct) role. Hence, $A_{H}$ is invariant to tariffs. ${ }^{10}$ Overall, both in the short-run and long-run, the theory from Sections 2 and 3 predict that, within exporter-industry groups, the least successful export sources, whether they be firms or exporter-

\footnotetext{
${ }^{10} \mathrm{~A}$ discussion of the analysis of free entry conditions under two-way trade is presented in the supplemental appendix, where given the nature of heterogeneity I need to exploit, the explicit characterization of the long-run model is intractable. However, I derive a sufficient condition and provide empirical evidence using an alternate dataset of bilateral trade and domestic production that suggests that Proposition 3 is empirically relevant.
} 
product pairs, increase trade the most after tariff liberalization. We now turn to empirically testing this prediction.

\section{Tariffs and bilateral trade: The US and the Uruguay Round}

In this section, I use detailed import and tariff data for the United States over the period 1989 to 2004 to estimate the degree to which the effects of tariffs and other trade shocks differ by pre-tariffcut import values. The import data is obtained from the UC Davis Center for International Data, and is described in Feenstra, Romalis, and Schott (2002). The HS8 tariff data is obtained from the US International Trade Commission, and also from the UC Center for International data. Bilateral exchange rates, which are used at the end of this section, are sourced from the Penn World Tables. I restrict attention to continuing HS10 products over the entire sample, which abstracts from new and/or dying HS10 codes. ${ }^{11}$ More information regarding the construction of the sample will be provided shortly. The level of refinement in the import data will be the Exporter-HS10 level, and I will henceforth refer to Exporter-HS10 pairs as "varieties".

To motivate the particular restrictions that I will impose on the sample for the empirical exercise, I will first discuss the nature of US MFN tariff liberalization over the period 1989-2004. Two particular characteristics of this round of ad-valorem tariffs cuts are presented in Figure 1 . In the left panel, I have plotted mean and median tariffs across HS8 products for each year, 1989-2004. The last year prior to the enactment of the Uruguay Round (1994) is denoted by the vertical line. Notably, there is very little movement in tariffs prior to the enactment of the Uruguay Round. Directly after, ad-valorem tariffs fell steadily, flattening out between 2000 and 2004. The slight up-tick in ad-valorem tariffs in 1997 is a result of the "tariffication" of some specific tariffs to advalorem measures. Overall, mean and median tariffs fell by roughly 50\%. Further, in the right-panel of Figure 1, I plot the empirical distribution of MFN tariffs in 1992 and 2004 (which will be the years over which I evaluate the effects of tariffs). Of note, US MFN reductions in the Uruguay Round doubled the number of MFN tariffs that were zero.

Given that US tariff reductions occurred only once, and essentially in two groups (75\% of reductions were finished in 2000, the rest by 2004), I will adopt a long-run analysis of tariff reductions. Indeed, the empirical strategy will be similar to Trefler (2004), using long differences to evaluate the effects of tariffs on bilateral imports. Specifically, I will measure import growth of varieties between

\footnotetext{
${ }^{11}$ See Pierce and Schott (2009) for a discussion and concordance for new and dying product codes.
} 
Figure 1: Ad-valorem MFN Tariffs: 1989-2004
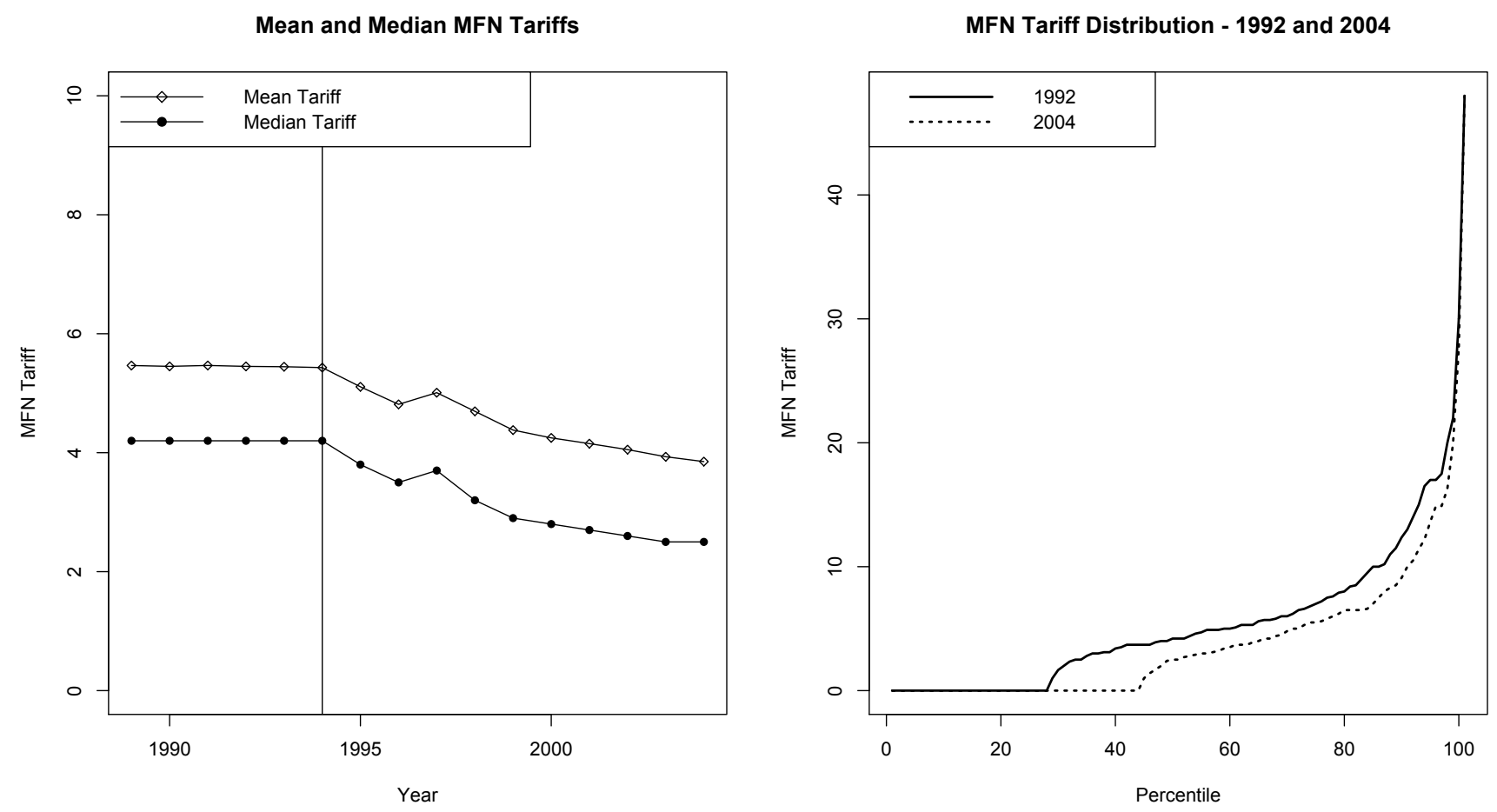

Notes: The left-hand plot depicts the mean and median MFN ad-valorem tariffs over the sample period. The right-hand panel illustrates the pre (1992) and post (2004) distirbution of MFN ad-valorem tariffs.

1992 and 2004 as a function of tariff cuts that occurred between 1992 and 2004, and initial import value in 1989 and $1990 .{ }^{12}$ Hence, the primary sample is restricted to those observations that report trade in 1992, 2004, and during the pre-period. This primary sample totals 74,587 Exporter-HS10 observations. As the model focuses on MFN tariffs cuts, I restrict the sample further to those Exporter-HS10 observations that do not report non-MFN trade over the entire sample period. This reduces the sample to 54,815 observations. Finally, as tariffs were meant to be frozen during GATT negotiations, I remove the small number of products for which there were reported tariff movements between 1989 and 1992, reducing the sample to the operational size of 54,149.

In Figure 2, I provide some illustrative evidence on the effect of ad-valorem MFN tariff reductions, and a differential effect of tariff reductions by market penetration before the tariff cut. To begin, focus on the left panel of Figure 2, where I plot relative trade growth for products that received an ad-valorem tariff cut and products that did not. To calculate relative trade growth, I first calculate the log of the ratio of imports in year $t$ to imports in 1992 for each Exporter-HS10

\footnotetext{
${ }^{12}$ I measure import growth from 1992 to allow for anticipatory effects of early drafts of Uruguay Round tariff cuts.
} 
Figure 2: Bilateral Trade Growth - 1989-2004
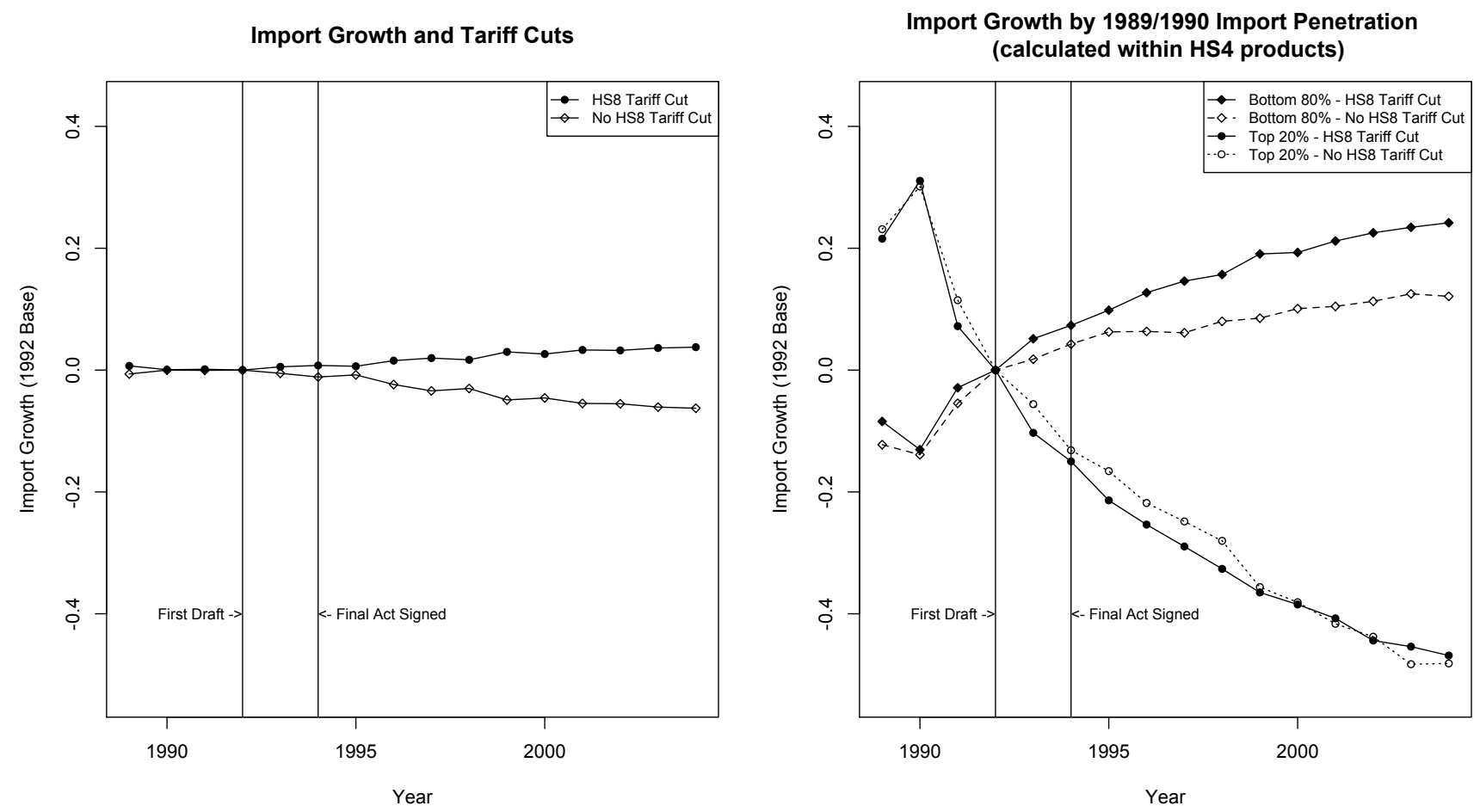

Notes: Both plots represent trade growth relative to 1992 for different groups. In the left-hand plot, log import growth at the Exporter-HS10 level is measured relative to 1992 and de-meaned by Exporter-HS4-Year Groups. These within growth rates are averaged across HS8 products that received a tariff cut, and separately for HS8 products that did not. The same technique is used in the right-hand plot, with the exception that the tariff cut - no tariff cut groups are broken down further to whether a given Exporter-HS10 observation is in the top 80\% of 1989-1990 import value within its respective Exporter-HS4 group.

pair. Then, for each year, I de-mean these growth rates across Exporter-HS4 pairs. Thus, in each year, average trade growth relative to 1992 is equal to zero. In the left panel of Figure 2, I have decomposed this "zero" into HS8 products that received a tariff cut, and HS8 products that did not. Further, I have denoted the first draft of the final act of the Uruguay round, which occurred at the end of 1991, and the year in which the final act was signed, 1994, by vertical black lines. Clearly, products that received a tariff cut experienced positive trade growth relative to those products that did not. More notably, trade growth rates for each product group were very close to one another prior to 1994. In Section 3 of the supplemental appendix, I present another chart showing that trade growth rates were similar all the way back to 1980. This suggests that after controlling for factors unrelated to tariff cuts (the Exporter-HS4-Year fixed effects), products which received a tariff cut during the Uruguay Round were not growing differently than those that did not receive a 
tariff cut. ${ }^{13}$ Given that good instruments for tariffs at the HS8 level do not exist for this analysis (to the author's knowledge), the fact that trade growth pre-WTO appears to be invariant to future tariffs cuts is particularly helpful.

In the right panel of Figure 1, I have further decomposed these demeaned growth rates by the relative position of each Exporter-HS10 observation within their respective Exporter-HS4 group. Precisely, I decompose the averages in the left-panel by whether or not, within each Exporter-HS4 group, an Exporter-HS10 variety was in the top 20\% of positive trade values over the period 19891990. Clearly, the group that benefited the most from a tariff cut relative to their no-tariff-cut control group were those Exporter-HS10 pairs that were in the bottom $80 \%$ of their given product category. In contrast, it is unclear whether varieties in the top $20 \%$ of their given Exporter-HS4 group benefited from tariff cuts relative to similar varieties in the no-tariff-cut HS8 control groups. Overall, the evidence in Figure 2 details a differential impact of ad-valorem MFN tariffs which is consistent with the theory developed in Section 3. I now test the robustness of these features using a broad set of regressions, and additional trade shocks

\section{Baseline Specification}

As discussed above, the object of interest will be the growth rate in Exporter-HS10 imports over the period 1992-2004. To measure the effects of tariff cuts, initial market penetration, and an interaction between the two on import growth, I estimate the following specification:

$$
\begin{aligned}
\log \left(\frac{v_{i, j, 04}}{v_{i, j, 92}}\right)= & \alpha_{m} \log \left(\frac{t_{i, 04}^{a v}}{t_{i, 92}^{a v}}\right)+\alpha_{m v} \log \left(\frac{t_{i, 04}^{a v}}{t_{i, 92}^{a v}}\right) \cdot \log \left(v_{i, j}^{\text {pre }}\right)+ \\
& \alpha_{z}\left(t_{i, 04}^{\text {specific }}-t_{i, 92}^{\text {specific }}\right)+\underset{z v}{\alpha_{z i}}\left(t_{i, 04}^{\text {specific }}-t_{i, 92}^{\text {specific }}\right) \cdot \log \left(v_{i, j}^{\text {pre }}\right)+ \\
& +\alpha_{v} \log \left(v_{i, j}^{\text {pre }}\right)+\text { Exp_Ind }_{+}+\epsilon_{i, j} \\
& -\underset{-}{ }
\end{aligned}
$$

Later, I will add-in exchange rates, though due to a number of issues with regressing trade growth on exchange rate growth, I will evaluate their effects separately from tariffs. In (14), import growth rates are labeled $\log \left(v_{i, j, 04} / v_{i, j, 92}\right)$, where $v_{i, j, r}$ measures the value of imports in nominal US dollars of

\footnotetext{
${ }^{13}$ This is a statistically robust statement. Regressing the log change in imports for each Exporter-HS10 observation between 1989 and 1992 on a dummy variable identifying a tariff cut and Exporter-HS4 fixed effects yields an insignificant relationship between pre-Uruguay round trade growth rates and future tariff cuts. Precisely,$$
\log \left(\frac{v_{i, j, 92}}{v_{i, j, 89}}\right)=\underset{[.0382]}{-.0370} \cdot \mathbf{I}\left(\frac{t_{i, 04}^{a} v}{t_{i, 94}^{a} v}<0\right)+\text { Exporter_HS4 }
$$

Standard errors are robust and clustered by Exporter and HS2 according to the procedure in Cameron, Gelbach, and Miller (2011).
} 
HS10 product $i$ from exporter $j$ in year $r$. The growth rate is regressed on a full interaction between two tariff shocks over the period 1992-2004, and the log of initial import revenues in 1989 and 1990, $\log \left(v_{i, j}^{p r e}\right)$. Again, this differs slightly from the theory in that the precise interaction suggested by the theory was the average value of imports at the firm-level in product $i$ from exporter $j$, and not the total value of imports in product $i$ from exporter $j$. However, as derived in Section 3, the link between the average firm-level import and total imports is monotone and positive when measuring imports within exporter-industry pairs and entry is at the exporter-industry level. Further, additional evidence from an alternate dataset suggests that this relationship is strongly monotone when simply evaluated within industries. ${ }^{14}$

The predicted sign is noted under each coefficient in (14). The first row presents the effects of ad-valorem MFN tariffs, which is the predominant trade shock over this period. Here, the theory predicts that within exporter-industries, the effects of higher tariffs should be negative only if import values are relatively small. I will measure ad-valorem tariffs as in Sections 2 and 3 , where $t_{i, r}^{a v}=1+\tau_{i, r}^{a v}$. Here, $\tau_{i, r}^{a v}$ is the percentage point ad-valorem MFN tariff for HS10 variety $i$ in year $r$ (though understanding that tariffs are set at the HS8 level). To calculate a measure of import elasticity, I will measure the change in tariffs using log differences, $\log \left(\frac{t_{i, 04}^{a v}}{t_{i, 92}^{a v}}\right)$, similar to the way in which I measure the change in import value for each Exporter-HS10 variety. Further, note that I measure the change in tariffs starting in 1992 because tariffs were essentially frozen during WTO negotiations, and tariff cuts began in 1994. A similar logic applies to the second row which estimates the effects of level changes to specific tariffs, where $t_{i, r}^{\text {specific }}$ is the per-unit tariff for product $i$ in year $r$. However, as discussed in Section 3, the conditions required for specific tariffs to disproportionately benefit small varieties are different from ad-valorem tariffs, and harder to satisfy. In the last row I include $\log \left(v_{i, j}^{\text {pre }}\right)$, which is required not only to prevent an obvious omitted variables problem with the interactions, but also to evaluate how broad changes to market competitiveness affect the composition of imports. For example, if ad-valorem tariffs are redefined as a systematic positive productivity shock to all exporters, the effects of this positive productivity shock will be larger in percentage terms for low-revenue export sources. Given that there was likely a large degree of positive technical change across all exporters within this period, I hypothesize that the level effect of $\log \left(v_{i, j}^{\text {pre }}\right)$ is negative. Finally, as discussed in Section 3, I will include a robust set of fixed effects at the exporter-industry level to absorb first-order changes in the number of potential exporters in each exporter-industry group, and to facilitate a precise link between import

\footnotetext{
${ }^{14}$ I have recently obtained a small subset of Colombian DIAN transaction level trade data (for 2003) and have evaluated the link between the average firm-level import value and the total value of imports within HS4 industries. Running regressions for HS4 industries separately, 88\% of HS4 industries have a positive and significant relationship between the total value of imports and the average firm-level import, and none have a significant negative relationship.
} 
values and elasticities. $^{15}$

The results from estimating (14) are presented in Table 1, where I have estimated 7 regressions that vary by the refinement of the fixed effect and whether or not there is an interaction with import value. Broadly speaking, all estimated signs support the theory, where all but those related to specific tariffs are highly significant at conventional levels. For the moment, focus on the effects of ad-valorem tariffs. First, in columns 1, 3, and 5, there is a significant and negative effect of ad-valorem tariffs when the level effect of tariffs can be estimated (all but Exporter-HS8 fixed effects). Indeed, we see that the average import elasticity with respect to tariffs is roughly -2. However, in columns 2, 4, and 6, when allowing for an interaction with average import values, we find Exporter-HS10 varieties that earn relatively little in the pre-period have a larger (negative) estimated elasticity. In contrast, relatively "successful" Exporter-HS10 varieties have a smaller estimated elasticity. When using Exporter-HS4 fixed effects, these estimated elasticities are illustrated in the left-hand panel of Figure 3. Clearly, in Figure 3, for a large share of the distribution of initial import values, we can reject the naive elasticity in favor of the differential elasticity (at the $95 \%$ level). In a moment, I precisely characterize the degree to which the naively estimated average elasticity is biased, and the degree to which the most successful varieties decrease exports to the US post-liberalization.

Next, focus on column 7 in Table 1, where I utilize Exporter-HS8 fixed effects. Here, since tariffs are set at the HS8 level, I cannot identify the average effect of tariffs. However, since $v_{i, j, p r e}$ varies by Exporter-HS10 pairs, one can estimate the differential effect. Indeed, we find that the differential effect is 2 times larger, more significant, and of the correct sign when compared with the other columns. However, one must take caution in generalizing based on this coefficient, since roughly $50 \%$ of observations are entirely absorbed by the fixed effects. Hence, the coefficient is identified using Exporter-HS8 industries that have a relatively large number of Exporter-HS10 varieties.

Next, I re-estimate the basic specification from Table 1 in Table 2 but instead using industry fixed effects rather than exporter-industry fixed effects. The original reasons for using exporterindustry fixed effects were to absorb first-order changes to the measure of entering firms in each exporter-industry pair and to provide a precise, monotone link between the average firm-level import and total imports. However, as discussed above (and detailed in Footnote 15), the latter monotone link is observed in an independent dataset within industries, and as such, the exporter-industry

\footnotetext{
${ }^{15}$ As for motivation outside of the theory, some exporter-industry pairs may be declining or growing due to development or a long-run adjustment toward different industries. This is particularly important in light of the Kehoe and Ruhl (2009) explanation for extensive margin growth, which is that price-shocks in countries like China are one factor driving the growth of the extensive margin. If price-shocks play a critical role, these exporter-industry trends should help control for them.
} 
fixed effect may not be required in practice for identification. Further, recent evidence (Buono and Lalanne (2011)) suggests that changes to the number of entering firms due to liberalization within the Uruguay Round was likely nil to modest (at best), and as such, first-order changes to entering firms in each exporter may be small or uncorrelated with other observables. Indeed, in Table 2, we find that with the exception of comparing the regression using HS8 fixed effects in Table 2 with that using Exporter-HS8 fixed effects in Table 1, the results do not change significantly. Hence, the bottom line from Tables 1 and 2 is that both within industries, and within exporter-industries, the Exporter-HS10 varieties that are relatively unsuccessful prior to liberalization gain the most from it.

Moving back to Table 1, I now focus attention on the effects of specific tariffs. While the coefficients are of the correct sign, the estimates are not precise at conventional levels. This insignificance might be a result of a number of factors. First, there were relatively few products with specific tariffs, which may make their effects difficult to estimate. Further, upon implementation of the Uruguay Round cuts some specific tariffs were replaced with ad-valorem tariffs. Finally, the insignificance may be a result of the empirical specification, where as discussed in Section 3, the demand conditions such that specific tariff liberalization disproportionately benefits small export sources is harder to satisfy. Indeed, this insignificance will change somewhat when adjusting the specification, and evaluating different "types" of products.

\section{Sample Selection}

A concern with the specification in (14) is that there is potentially a large degree of model-driven sample selection. That is, to be included in the sample, observations must have positive imports in 1989-1990, 1992, and 2004. While the analysis should be understood as being one relevant for continuing varieties, care should be taken in interpreting the results in-light of this potentially

selected sample. Unfortunately, given the level of detail in the analysis, instruments to correct properly for any selection are not available. Instead, to get a sense of the degree to which sample selection may be biasing the differential effect of tariff cuts, I will offer a supplementary regression estimating the factors associated with attrition, and also provide an alternate specification that removes a large portion of the model-driven sample selection.

First, consider the issue of attrition from the sample. The dependent variable that has been used thus far is a log growth rate between 1992 and 2004. Naturally, one might expect small import values to be more likely affected by idiosyncratic shocks, and as such, the sample is likely selected on large continuing varieties. However, for there to be a bias in the differential impact of tariffs, this selection not only should be related to tariffs, but also an interaction with initial size. In 
supplementary regressions (available upon request), it appears that this is not the case, and hence, any attrition from the sample related to variety size is not correlated with tariff cuts. ${ }^{16}$

As a second check for sample selection, I now use alternate measures of both initial market penetration and trade growth that do not cause as large of a specification-based selection problem. In terms of the former, I will measure initial market penetration in millions of US\$ (no logs). To provide an alternate measure of trade growth, I will define trade and ad-valorem tariff growth using the mid-point formula. ${ }^{17}$ The use of the mid-point formula has its advantages and disadvantages. On the positive side, rather than dropping an observation if $v_{i, j, 04}=0$ or $v_{i, j, 92}=0$, one can calculate a growth rate at the mid-point if at least one is positive. Further, large positive or negative log growth rates are bounded using the mid-point formula. However, on the negative side, the midpoint formula is in fact an approximation, so while it allows for more observations to remain in the sample for estimation, we are introducing measurement error by using this formula.

The results from using the mid-point formula are presented in Table 3. Qualitatively, the results are consistent with the baseline results in Table 1. Again, the use of the mid-point formula to calculate percent changes introduces measurement error into the growth rates. However, note that this would tend to attenuate the estimates for elasticities downward, and given that we are finding precise estimates already that are in-line with the theory, this measurement error is not a huge concern in terms of interpreting the estimates from this robustness check. More importantly, by adding more than twice as many observations as before, the qualitative results remain, and provides additional evidence suggesting that sample selection is not causing a qualitative bias.

\section{Does liberalization increase imports of all varieties?}

A novel focus of this paper has been the prediction that some bilateral trade flows fall after advalorem tariff liberalization. Indeed, in Proposition 2, I show that there exist conditions such that the most successful export sources, as measured by revenue, reduce exports to the import market

\footnotetext{
${ }^{16}$ For example, regressing positive imports in $2004\left(\mathbf{I}\left(v_{i, j, 04}>0\right)\right)$ on imports in 1992 and interactions with the two types of tariff cuts, we get the following:

$$
\begin{aligned}
\mathbf{I}\left(v_{i, j, 04}>0\right)= & \underset{(0.39)}{-0.227} \log \left(\frac{t_{i, 04}^{a v}}{t_{i, 92}^{a v}}\right)+\underset{(0.029)}{0.018} \log \left(\frac{t_{i, 04}^{a v}}{t_{i, 92}^{a v}}\right) \cdot \log \left(v_{i, j, 92}\right)+\underset{(0.003)}{0.024} \log \left(v_{i, j, 92}\right) \\
& +\underset{(0.195)}{0.290}\left(t_{i, 04}^{\text {specific }}-t_{i, 92}^{\text {specific }}\right)-\underset{(0.016)}{0.025}\left(t_{i, 04}^{\text {specific }}-t_{i, 92}^{\text {specific }}\right) \cdot \log \left(v_{i, j, 92}\right)+\text { Exp_HS4 }
\end{aligned}
$$

In terms of other fixed effect specifications, the coefficient on ad-valorem tariffs (no interaction) is significant at the $90 \%$ level with Exporter-HS2 fixed effects, and the coefficient on specific tariffs is significant at the $90 \%$ level when using Exporter-HS6 fixed effects. No interactions are significant.

${ }^{17}$ Precisely, the mid-point formula is written as $\% \Delta X_{1,0}=\frac{X_{1}-X_{0}}{\left(X_{1}+X_{0}\right) / 2}$
} 
Figure 3: Summary of Bias in Average Elasticities

Predicted Import Elasticities and Initial Import Value

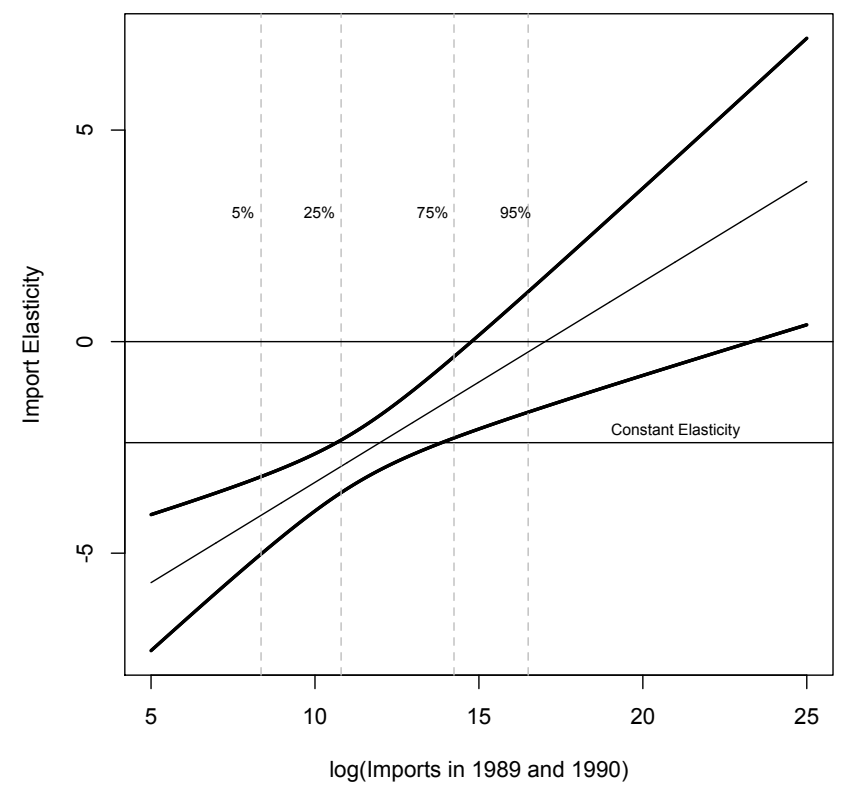

Distribution of Exporter-HS4 Elasticities

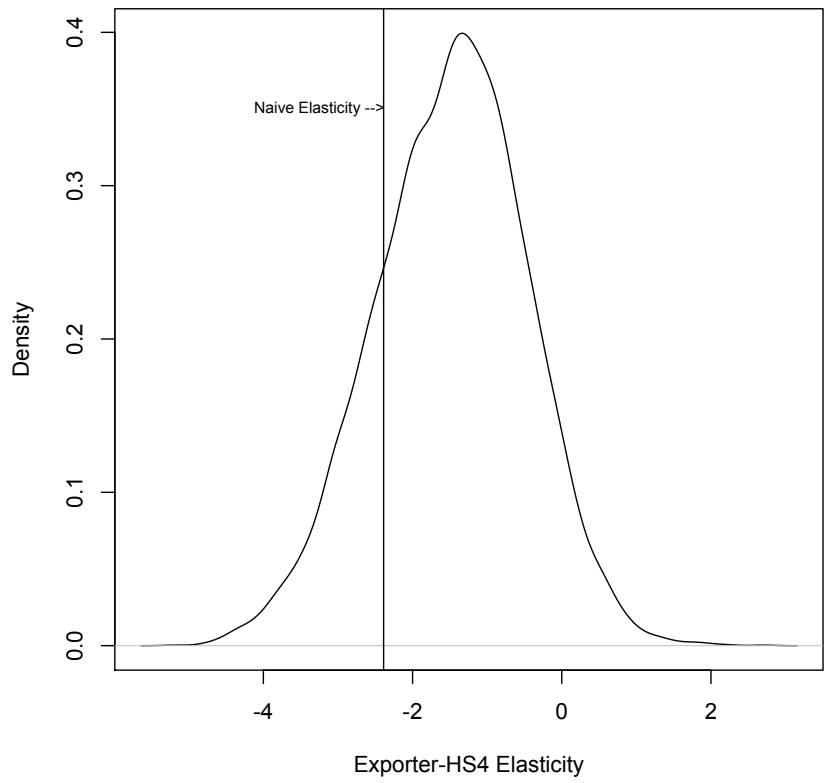

Notes: The left-hand plot depicts the estimated within Exporter-HS4 tariff elasticity as a function of log imports in 1989 and 1990. The heavy black lines represent 95\% confidence intervals, and the vertical dashed lines represent $5 \%, 25 \%, 75 \%$, and $95 \%$ percentiles of initial imports. The right-hand plot reports the distribution of Exporter-HS4 aggregate elasticities relative to the naively estimated constant elasticity (vertical line).

after liberalization. Further, this is a feature of the analysis that distinguishes the theoretical model from those based on CES preferences. To examine this possibility, first note that in the left-hand panel of Figure 3, 20\% of varieties have an estimated elasticity which is not significantly different from zero at the 95\% confidence level (using Exporter-HS4 fixed effects). To provide a complete summary of the results relative to this prediction, in Table 4, I report the predicted tariff elasticities and standard errors for Exporter-HS10 varieties at the 90th, 95th and 99th percentiles of $\log \left(v_{i, j}^{p r e}\right)$ for different sets of fixed effects. Here, we find that at the 90 th percentile of revenues, the marginal effect of tariffs is not significantly different from zero for all regressions. At the 95th and 99th percentiles, the predicted marginal effect of tariffs is positive for some regressions, though still not significant. In a moment, I will recalculate these elasticities for products that are more likely to confirm the prediction that ad-valorem tariff liberalization can kick out the most successful suppliers. 


\section{Aggregation Bias}

Broadly, the results in Table 1 suggest that failing to account for heterogenous demand elasticities results in a biased estimate of the average elasticity of trade value with respect to tariffs. To precisely calculate the degree to which the average elasticity is biased, I first calculate the true elasticity for exporter $l$ in industry $j$ based on the market shares (in value) and individual elasticities of the varieties,

$$
\epsilon_{l, j}=\sum_{i \in \Psi_{l, j}}\left(\frac{V_{i, j}}{\sum_{i \in \Psi_{l, j}} V_{i, j}} \epsilon_{i, j}\right),
$$

where $\Psi_{l, j}$ is the set of HS10 products within industry $j$ exported to the US by country $l$. Calculating the true elasticity for each exporter-industry group after each regression in Table 1, we find that there is a substantial bias in assuming that tariff elasticities are invariant to import values. Table 4 summarizes the "naive" elasticity estimated without an interaction between tariffs and import values, and the average and median true elasticities for each regression (across exporter-industry groups). The right-hand panel of Figure 3 details the distribution of these elasticities when using

Exporter-HS4 fixed effects, and the naively estimated average elasticity. Overall, the data suggests that there is a substantial bias in assuming that elasticities are invariant to market shares, where the true elasticity is roughly one point less elastic than the naive average elasticity. Relative to the typical average tariff elasticity of bilateral imports (roughly -2), this bias is substantial.

\section{HS8 Industry Characteristics}

In the previous section, I provided evidence that trade shocks affect US imports in a way consistent with a variable elasticity demand system. In particular, the response to MFN ad-valorem tariff liberalization is more pronounced for varieties that are relatively unsuccessful prior to tariffs being cut. However, this effect may differ across industry types based on the fundamental characteristics of demand. In this section, I evaluate the response to trade shocks across industry-types.

In Section 2 and Section 3, a key parameter was the degree of substitution in the differentiated industry. If varieties are relatively substitutable, there was a differential response to tariffs such that in some cases imports from the largest suppliers fell following tariff liberalization. To measure the level of substitutability within each differentiated industry, I merge estimates of the elasticity of substitution, $\sigma$, by HS10 product, from Broda and Weinstein (2006). While these estimates are generated from a CES demand system, they should provide an approximation of the level of substitution within products and industries.

To classify industries, I construct import-weighted averages of $\sigma$ by HS8 industry (using 1989- 
1990 imports as weights), which is the level at which tariffs are set. Then, I classify industries as above or below the sample median value of $\sigma$, and estimate separate slope coefficients for each group, high substitution and low substitution. The results are presented in Table 5, where we find a sharp dichotomy between the two industry types. For industries with relatively low substitution, I find that imports are not particularly sensitive to changes in ad-valorem tariffs or specific tariffs. In contrast, for those industries with relatively high substitution within the differentiated industry, we find a very significant and differential effect of ad-valorem tariff liberalization. Further, in Table 4, I calculate the estimated ad-valorem tariff elasticities for the largest exporters within highsubstitution industries. As predicted in Proposition 2, the largest varieties in high-substitution industries have a positive estimated tariff elasticity of bilateral imports. In some cases, higher advalorem tariffs significantly increase imports. Overall, the results in Table 5 and the bottom panel of Table 4 suggest that support for the model is more pronounced in industries that exhibit a much stronger elasticity of substitution across varieties within an industry.

Next, I examine how the level of exporter concentration within a given product influences the differential effect of tariffs within the same product. The effects of exporter concentration on bargained tariff cuts have been examined by Ludema and Mayda (2009), where they show that import markets with a higher concentration of export sources are forced to engage in larger tariff concessions. This is confirmed empirically using a US case study over a similar time-period to that in this paper. ${ }^{18}$ In the specifications above, the exporter-industry fixed effects should control for mean differences exporter concentration. However, if exporter concentration has unmodeled and unobserved effects on the differential response to tariffs, the above estimates may be contaminated. Indeed, exporter concentration may also pick-up the effects of substitution, where heterogeneity will be more pronounced in observable revenues when varieties are highly substitutable. ${ }^{19}$

To examine these issues, I first aggregate trade from the Exporter-HS10 level to the ExporterHS8 level over the period 1989-1990. Then, I construct a Hirschman-Herfindahl index (HHI) for each HS8 product based on the market share of exporters. After identifying the median value of HHI across the entire sample, I group each product into "Low" and "High" measures of HHI. To examine the effects of exporter concentration, I interact dummy variables identifying low and high HHI products with all slope terms in (14). The results are presented in the left panels of Table 6. Here, we find distinct differences in the effects of tariff liberalization for products that likely

\footnotetext{
${ }^{18}$ The intuition for this result is that since tariff cuts in the GATT/WTO are determined via extensive bargaining, agents in concentrated export sectors are less likely to free-ride off of tariff concessions negotiated by other exporters (since the other exporters are small in comparison). Thus, when exporter concentration is relatively large, free-riding is minimized and bargained tariff cuts in the import market are larger.

${ }^{19}$ This is proven rigorously for a capital investment model in Spearot (2012).
} 
have very different industry structures, where only those products with below median HHI (low concentration) yield estimates which are consistent with the theory. In particular, for low HHI products, there is a sharp differential effect of tariff liberalization that is consistent with the theory. In contrast, for products with high HHI, the effect is less significant and tends to operate in the other direction. As high HHI products do not seem to support the theoretical model, this suggests that high HHI products may have different underlying demand characteristics, or that supply conditions are more favorable for suppliers which are highly successful relative to their peers. ${ }^{20}$

\section{Exchange Rates}

In Section 3, I detailed the effects of two types of tariffs: ad-valorem and specific. However, the basic intuition of the model applies to exchange rate shocks, where the intuition is similar to ad-valorem tariffs, though only applied within exporter-industries. Subject to a foreign currency depreciation, imports increase only for those products that are sold at relatively high absolute elasticities. Again, within exporter-industry groups, these are the low revenue varieties.

To test this prediction, I first run the following simple specification on the sample of HS8 products for which there were no tariff movements, specific or ad-valorem.

$$
\log \left(\frac{v_{i, j, 04}}{v_{i, j, 92}}\right)=\alpha_{-v} \log \left(\frac{e_{j, 04}}{e_{j, 92}}\right) \cdot \log \left(v_{i, j}^{p r e}\right)+\underset{-}{\alpha_{v}} \log \left(v_{i, j}^{p r e}\right)+\operatorname{Exp} I n d+\epsilon_{i, j}
$$

Here, I interact the $\log$ change in exchange rates, $\log \left(\frac{e_{j, 04}}{e_{j, 92}}\right)$, with $\log \left(v_{i, j}^{p r e}\right)$, where $e_{j, r}$ is the foreign to US exchange rate for exporter $j$ in year $r$. Of note, the level effect of exchange rates will be absorbed by the fixed effects, and thus all that remains is the interaction. Also, note that the predicted sign on the interaction is different from tariffs since a foreign depreciation makes foreign varieties more competitive in the import market, but is measured positively in $\log \left(\frac{e_{j, 04}}{e_{j, 92}}\right)$. Finally, note that endogeneity, while an issue in this regression, will likely be second order. Given that I am estimating within exporter-industry groups, an endogeneity issue that would cast doubt on the sign of $\alpha_{e v}$ would require that unobserved positive import value shocks on Exporter-HS10 observations, after accounting for very detailed fixed effects, tend to appreciate the aggregate exporter currency. Given that the exchange rate is aggregate, it is highly unlikely that unobserved variation within detailed exporter-industry groups is driving aggregate fluctuations in exchange rates.

The results from estimating (15) are presented in Table 7. In the first three columns the sign

\footnotetext{
${ }^{20}$ Indeed, if exporter concentration is a result of superior supply-side flexibility rather than differences in average costs, the differential effect described in Section 2 can be overturned. Theory along these lines for purely price taking firms is available upon request.
} 
on the interaction between import value and the percent change in exchange rates is negative and significant, as the theory predicts. In the second three columns, the model is estimated using all products, including those with tariff movements (for which we control). Here, we find that while more subtle, the effects of exchange rates are still significant. In all columns, the parameter estimates are quite small, which is not shocking given that exchange rates may follow a random walk while the other trade shocks exhibit greater persistence. Finally, despite the addition of exchange rates, the signs and significance on the tariff shocks are similar to the baseline results in Table 1.

\section{Conclusion}

This paper presented a simple model of import market liberalization and bilateral trade. Theoretically, I show that when cost heterogeneity yields differences in demand elasticities, trade liberalization necessarily increases imports only of varieties that are high cost, which are sold at relatively high demand elasticities and earn relatively low revenues. In evaluating the model using a case study of US tariff reductions resulting from the Uruguay Round, I find robust support for the model.

The most promising extensions of this work are policy-related papers to evaluate how elasticity heterogeneity may induce a bias in projections over welfare calculations, and to evaluate whether the current rules of the WTO are sufficient to guarantee efficiency in trade negotiations conditional on the effects discussed in this paper. Regarding the former, preliminary calculations in the supplementary appendix suggest that when costs are distributed Pareto, applying an aggregate trade elasticity to all countries and firms will over-estimate the negative impact of tariffs on welfare. Intuitively, applying the aggregate elasticities to large suppliers ignores the fact that these suppliers are more likely to exhibit a muted response to tariff liberalization, and hence, the true negative impact of tariffs on consumer surplus is smaller.

In the second extension, the empirics document natural economic forces that are in direct conflict with the intent of the central tenet of the WTO: the principle of non-discrimination. That is, while non-discrimination requires that countries apply and liberalize tariffs equally across MFN exporters, the benefits of tariff reductions do indeed discriminate along natural margins. The question then becomes, is non-discrimination a sensible policy? ${ }^{21}$ Or should countries be allowed to discriminate along some margin? As in Saggi (2004), countries left unconstrained will set higher

\footnotetext{
${ }^{21}$ As detailed in Jackson (1997), there are three traditional arguments which support the use of MFN. One is that MFN prevents policies which distort bilateral patterns of comparative advantage. Further, some argue that MFN results in more liberalization than under preferential systems. Finally, others argue that allowing for discriminatory tariffs would increase the costs of rule formation, where many tariff lines would be more costly to impose and enforce when compared to a single tariff line applied to all exporters.
} 
tariffs on low-elasticity products, thereby exacerbating the disadvantage to high revenue suppliers under discrimination. Hence, it seems that non-discrimination, while not necessarily helpful to high revenue varieties, is likely preventing optimal discrimination that would otherwise make their situation worse. Indeed, successful exporters, who tend to lead WTO negotiations, may be more likely to support strict rules on bilateral agreement formation and other forms of discrimination that make it harder for countries to discriminate against their exporters. Evaluating this idea theoretically and empirically is left for future work. 


\section{References}

Anderson, J., And E. VAn Wincoop (2003): "Gravity with Gravitas: A Solution to the Border Puzzle," The American Economic Review, 93(1), 170-192.

Arkolakis, C. (2010): "Market Penetration Costs and the New Consumers Margin in International Trade," The Journal of Political Economy, 118(6), 1151-1199.

Baldwin, R., And J. Harrigan (2011): "Zeros, Quality, and Space: Trade Theory and Trade Evidence," American Economic Journal: Microeconomics, 3(2), 60-88.

Behrens, K., And Y. Murata (2011): "Trade, competition, and efficiency," Journal of International Economics.

Bernard, A., S. Redding, and P. Schott (2011): "Multiproduct Firms and Trade Liberalization," The Quarterly Journal of Economics, 126(3), 1271-1318.

Broda, C., And D. Weinstein (2006): "Globalization and the Gains from Variety," Quaterly journal of economics, (2), 541-585.

Buono, I., and G. Lalanne (2011): "The Effect of the Uruguay Round on the Intensive and Extensive Margins of Trade," Journal of International Economics.

Cameron, A., J. Gelbach, and D. Miller (2011): "Robust Inference With Multiway Clustering," Journal of Business and Economic Statistics, 29(2), 238-249.

Campbell, J., and H. Hopenhayn (2005): "Market Size Matters," Journal of industrial economics, 53(1), 1-25.

Feenstra, R. (1994): "New Product Varieties and the Measurement of International Prices," The American Economic Review, pp. 157-177.

Feenstra, R., J. Romalis, and P. Schott (2002): "US Imports, Exports, and Tariff Data, 1989-2001," Discussion paper, National Bureau of Economic Research.

Feenstra, R., And D. Weinstein (2010): "Globalization, Markups, and the US Price Level," Discussion paper, National Bureau of Economic Research.

Foster, L., J. Haltiwanger, and C. Syverson (2008): "Reallocation, Firm Turnover, and Efficiency: Selection on Productivity or Profitability?," The American Economic Review, pp. $394-425$.

Hallak, J., And J. Sivadasan (2009): "Firms' Exporting Behavior under Quality Constraints," Discussion paper, National Bureau of Economic Research.

Head, K., R. Jing, And J. Ries (2007): "Import Sourcing of Chinese Cities: Order versus Randomness," . 
Helpman, E., M. Melitz, and Y. Rubinstein (2008): "Estimating Trade Flows: Trading Partners and Trading Volumes," Quarterly Journal of Economics, 123, 441-487.

Hummels, D., and A. Skiba (2004): "Shipping the Good Apples Out? An Empirical Confirmation of the Alchian-Allen Conjecture," The Journal of Political Economy, 112(6), 1384-1402.

Jackson, J. (1997): The World Trading System: Law and Policy of International Economic Relations. The MIT press.

Johnson, R. (2011): "Trade and Prices with Heterogeneous Firms," Journal of International Economics.

Kehoe, T., And K. Ruhl (2009): "How Important is the New Goods Margin in International Trade?," .

Ludema, R., And A. Mayda (2009): "Do Countries Free Ride on MFN?," Journal of international Economics, 77(2), 137-150.

Manova, K. (2008): "Credit Constraints, Heterogeneous Firms, and International Trade," NBER Working Papers.

Mayer, T., M. Melitz, and G. Ottaviano (2011): "Market size, Competition, and the Product Mix of Exporters," Discussion paper, National Bureau of Economic Research.

Melitz, M., and G. Ottaviano (2008): "Market Size, Trade, and Productivity," Review of Economic studies, 75(1), 295-316.

Pierce, J., And P. Schott (2009): "Concording US Harmonized System Categories Over Time," Discussion paper, National Bureau of Economic Research.

Rodríguez-López, J. (2011): "Prices and Exchange Rates: A Theory of Disconnect," The Review of Economic Studies, 78(3), 1135-1177.

Rose, A. (2004): "Do We Really Know That the WTO Increases Trade?," American Economic Review, pp. 98-114.

SAGGI, K. (2004): "Tariffs and the Most Favored Nation Clause," Journal of International Economics, 63(2), 341-368.

Saggi, K., And N. SAra (2008): "National Treatment at the WTO: The Role of Product and Country Heterogeneity," International Economic Review, 49(4), 1365-1394.

Spearot, A. (2012): "Firm Heterogeneity, New Investment, Acquisitions," forthcoming, Journal of Industrial Economics.

Subramanian, A., and S. Wei (2007): "The WTO Promotes Trade, Strongly but Unevenly," Journal of International Economics, 72(1), 151-175. 
Trefler, D. (2004): "The Long and Short of the Canada-US Free Trade Agreement," American Economic Review, pp. 870-895. 


\section{A General Demand Function}

\section{A.1 Generalization of Proposition 1}

To derive that the direct effects of tariffs on import value are negative for all firms, but larger on a percentage basis for smaller firms, I first assume that each firm faces a downward sloping demand function of the form $P\left(q_{i}, Q\right)$ where $q_{i}$ represents the quantity of imports from exporter $i$ and $Q$ represents total imports from all exporters. Treating itself small relative to $Q$, exporter $i$ maximizes the following profit function:

$$
\Pi=\max _{q_{i}}\left\{\frac{P\left(q_{i}, Q\right)}{t} \cdot q_{i}-c_{i} \cdot q_{i}\right\}
$$

Suppressing $i^{\prime} s$ for notational convenience, and defining $n(q)$ as the inverse price elasticity of demand, the first order condition for this maximization problem is written as

$$
P(q, Q)(n(q)+1)=c t
$$

where $n(q) \in(-1,0)$. As is well known, the price that the exporter receives, $\frac{P(q, Q)}{t}$, is a mark-up, $\frac{1}{n(q)+1}$ over marginal costs. To ensure that this firm-level choice is indeed a maximum, I assume that the second-derivative of the objective function is negative. Differentiating the marginal revenue function and factoring out common terms, the second order condition is satisfied if:

$$
\frac{(n(q)+1) P(q, Q)}{q}\left(n(q)+\frac{q}{n(q)+1} \frac{\partial n(q)}{\partial q}\right)<0
$$

Hence, the second order condition is satisfied if:

$$
s(q) \equiv n(q)+\frac{q}{n(q)+1} \frac{\partial n(q)}{\partial q}<0
$$

Technically, $s(q)$ is the elasticity of marginal revenue with respect to quantity, where the second order condition requires that this elasticity is negative. How this elasticity changes for different quantities will be crucial for the results.

The object of interest in Section 2 is the value of trade earned by a given export source, which can be written as:

$$
V=q \cdot \frac{P(q, Q)}{t}=q \cdot \frac{1}{n(q)+1} \cdot c
$$

Holding $Q$ fixed (as in Proposition 1), log differentiating with respect to $t$, and rearranging, we get

$$
\epsilon_{v, t}=\epsilon_{q, t}\left(1-\frac{q}{(n(q)+1)} \frac{\partial n(q)}{\partial q}\right)
$$


where $\epsilon_{v, t}$ and $\epsilon_{q, t}$ are (respectively) the elasticities of $V$ and $q$ with respect to $t$. Note that there are two components in $\epsilon_{v, t}$. In the first, $\epsilon_{q, t}$ is the elasticity of quantity with respect to tariffs. Holding the markup constant, lower quantities with higher tariffs will obviously reduce the value of trade proportionally. The second effect is $\epsilon_{q, t}$ scaled by $-\frac{q}{(n(q)+1)} \frac{\partial n(q)}{\partial q}$, which is the elasticity of the mark-up with respect to quantity. How the elasticity of the mark-up changes with quantity will also be central to the general results.

To build intuition, I will first examine $\epsilon_{q, t}$, and the effects of $q$ on this elasticity. Log-differentiating the price mark-up equation in (15), we have:

$$
\frac{1}{P} \frac{\partial P}{\partial q} \frac{\partial q}{\partial t}+\frac{1}{n(q)+1} \frac{\partial n(q)}{\partial q} \frac{\partial q}{\partial t}=\frac{1}{t}
$$

Rearranging as elasticities, and substituting $s(q)$ to ease notation, we get:

$$
\epsilon_{q, t}=\frac{1}{n(q)+\frac{q}{n(q)+1} \frac{\partial n(q)}{\partial q}}=\frac{1}{s(q)}<0
$$

where the inequality follows due to the second order conditions. Differentiating $\epsilon_{q, t}$ with respect to $q$, we get:

$$
\frac{\partial \epsilon_{q, t}}{\partial q}=-\frac{1}{s(q)^{2}} \frac{\partial s(q)}{\partial q}
$$

Hence, the elasticity of import quantity with respect to tariffs is rising (less elastic) in quantity if $\frac{\partial s(q)}{\partial q}<0$, or put differently, if the elasticity of marginal revenue is falling in quantity. As examples, $\frac{\partial s(q)}{\partial q}<0$ is satisfied for linear demand, but not satisfied for CES (where $\frac{\partial s(q)}{\partial q}=0$ ).

It is worth taking a moment to study how this condition would change if tariffs were instead per-unit. For the per-unit case, the first order condition is written as:

$$
P(q, Q)(n(q)+1)=c+z
$$

Log-differentiating the price mark-up equation in (19), rearranging, and defining $\epsilon_{q, z}$ as the elasticity of import quantity with respect to the specific tariff, we have:

$$
\frac{1}{\epsilon_{q, z}} \frac{\partial \epsilon_{q, z}}{\partial q}=-s(q)-\frac{q}{s(q)} \frac{\partial s(q)}{\partial q}
$$

Here, $\frac{\partial s(q)}{\partial q}<0$ is no longer sufficient for $\frac{\partial \epsilon_{q, z}}{\partial q}>0$. The requirement is indeed more strict, where $\frac{\partial \epsilon_{q, z}}{\partial q}>0$ if and only if $\frac{\partial s(q)}{\partial q}<-\frac{(s(q))^{2}}{q}$. Hence, the differential response to tariffs examined in the paper is supported by a wider class of demand systems with ad-valorem tariffs. 
Shifting attention back to trade value, substituting the equation for $\epsilon_{q, t}$ into $\epsilon_{v, t}$, we get:

$$
\epsilon_{v, t}=\frac{1}{s(q)}(1+\underbrace{n(q)-s(q)}_{\epsilon_{m, q}})<0
$$

The inequality follows since $s(q)<0, n(q) \in(-1,0)$, and hence, $1+n(q)-s(q)>0$. Further, note that $n(q)-s(q)=\epsilon_{m, q}$, where $\epsilon_{m, q}$ is the elasticity of the mark-up with respect to quantity.

Differentiating $\epsilon_{v, t}$ with respect to $q$, we get:

$$
\frac{\partial \epsilon_{v, t}}{\partial q}=\underbrace{-\frac{1}{s(q)^{2}} \frac{\partial s(q)}{\partial q}}_{\frac{\partial \epsilon_{q, t}}{\partial q}}(1+n(q)-s(q))+\frac{1}{s(q)}(\underbrace{\frac{\partial n(q)}{\partial q}-\frac{\partial s(q)}{\partial q}}_{\frac{\partial \epsilon_{m, q}}{\partial q}})
$$

The first terms represent changes to $\epsilon_{q, t}$ holding the elasticity of the mark-up with respect to quantity $(n(q)-s(q))$ constant, and the second terms represent changes to the elasticity of the mark-up with respect to quantity holding $\epsilon_{q, t}$ constant. Overall, $\frac{\partial \epsilon_{v, t}}{\partial q}>0$ if and only if:

$$
\frac{\partial s(q)}{\partial q}<\frac{\partial n(q)}{\partial q} \frac{s(q)}{(1+n(q))}
$$

The condition in (21) requires that the elasticity of the marginal revenue curve with respect to quantity is not too high (though not necessarily negative). As derived in (20), $\epsilon_{v, t}$ is affected directly by both changes to equilibrium quantities and the mark-up, where the effects may go in different directions depending on the value of $\frac{\partial s(q)}{\partial q}$. However, when evaluating both channels together, which are a function of the same underlying demand curve, the negative response to liberalization is softened for high $q$ firms if and only if $\frac{\partial s(q)}{\partial q}$ is relatively low.

In terms of the fundamental demand characteristics, the condition in (21) can be sharpened when written as a function of how the inverse elasticity of demand changes with quantity.

$$
\frac{\partial^{2} n(q)}{\partial q^{2}}<-\frac{2}{q} \underbrace{\left(1-\frac{q}{1+n(q)} \frac{\partial n(q)}{\partial q}\right)}_{>0} \frac{\partial n(q)}{\partial q}
$$

Hence, the key to tariff liberalization disproportionately benefiting small varieties is ultimately a balance between the first and second derivatives of the inverse elasticity of demand, which in-turn dictate how the marginal revenue function and the markup both change with higher quantities. As a final point, note that a simple sufficient condition for this result is that $\frac{\partial n(q)}{\partial q}<0$ and $\frac{\partial^{2} n(q)}{\partial q^{2}} \leq 0$, which is more than satisfied by linear demand (for which $\frac{\partial^{2} n(q)}{\partial q^{2}}<0$ ), and not by CES (where $\frac{\partial n(q)}{\partial q}=0$ and $\left.\frac{\partial^{2} n(q)}{\partial q^{2}}=0\right)$. 


\section{A.2 Generalization of Proposition 2}

Next, I establish when the most successful export sources reduce exports to the import market after a reduction in ad-valorem tariffs. To ease notation, I will write the inverse demand function for variety $j$ as $P^{j}=P\left(q_{j}, Q\right)$, and partial derivatives of the function will be labeled with subscripts. I assume that $P_{1}<0$ and $P_{2}<0$ for $q>0$ and $Q>0$. Using this notation, the first order condition for production is written as:

$$
P_{1}^{j} q_{j}+P^{j}=c_{j} t
$$

I assume that the second order condition is satisfied, along with varieties being strategic substitutes with aggregate quantity. Respectively, these conditions are written as:

$$
\begin{gathered}
P_{11}^{j} q_{j}+2 P_{1}^{j}<0 \\
P_{12}^{j} q_{j}+P_{2}^{j}<0
\end{gathered}
$$

Finally, for this setup, note that the elasticity of aggregate quantity with respect to tariffs, $\epsilon_{Q, t}$, can be written as

$$
\epsilon_{Q, t}=\frac{\sum_{i=1}^{N}\left(\frac{c_{i} t}{Q\left(P_{11}^{i} q_{i}+2 P_{1}^{i}\right)}\right)}{1+\sum_{i=1}^{N}\left(\frac{P_{12}^{i} q_{i}+P_{2}^{i}}{P_{11}^{i} q_{i}+2 P_{1}^{i}}\right)}<0
$$

where the inequality follows from the second order and strategic substitute conditions.

To derive the elasticity of trade value with respect to tariffs, I will define the value of imports that accrues to the producer as $V_{j}=\frac{P^{j} q_{j}}{t}$. Log differentiating with respect to $t, q_{j}$ and $Q$, and defining $\epsilon_{v_{j}, t}, \epsilon_{q_{j}, t}$, and $\epsilon_{Q, t}$ as the tariff elasticities of $V_{j}, q_{j}$, and $Q$, respectively, we have:

$$
\epsilon_{v_{j}, t}=\underbrace{\left(\frac{P_{1}^{j}}{P^{j}} q_{j}+1\right) \epsilon_{q_{j}, t}-1}_{\text {Focus of Proposition } 1}+\frac{P_{2}^{j}}{P^{j}} Q \epsilon_{Q, t}
$$

Though written differently, the braced terms are the focus of the results in Appendix A.1, where $\epsilon_{v_{j}, t}$ is generally negative but increasing in quantity when the second derivative of the own (partial) inverse elasticity of demand is "low enough". I assume that this condition holds, focusing attention on the other partial elasticities within the inverse demand function. Specifically, to ensure that $\frac{\partial \epsilon_{v_{j}, t}}{\partial q}>0$ in the presence of aggregate effects, I seek conditions such that $\frac{P_{2}^{j}}{P^{j}} Q \epsilon_{Q, t}$ is weakly increasing in $q$. Given that $\epsilon_{Q, t}<0$, and treating $q$ as small relative to $Q$ (i.e. holding $Q \epsilon_{Q, t}$ constant), this is guaranteed if:

$$
\frac{P_{2}^{j}}{P^{j}} \leq \frac{P_{12}^{j}}{P_{1}^{j}}
$$


This is a stronger condition than strategic substitutes, where aggregate quantity has a stronger negative effect on inverse demand than it does on the derivative of inverse demand. ${ }^{22}$ However, keep in mind that this is simply a sufficient condition that the largest suppliers, who according to Proposition 1 experience the smallest direct effects of tariff cuts, experience aggregate effects that do not overturn the qualitative result that $\frac{\partial \epsilon_{v_{j}, t}}{\partial q_{j}}>0$. I will come back to this condition at the end of the proof.

Next, I examine the effects of liberalization for the largest varieties. Imposing the first order condition for the largest variety, $P_{1}^{j} q_{j}+P^{j}=0$, and defining $\epsilon_{P^{j}, Q}=\frac{P_{2}^{j} Q}{P^{j}}, \epsilon_{v_{j}, t}>0$ if:

$$
\epsilon_{p^{j}, Q}<\frac{1}{\epsilon_{Q, t}}
$$

Since $\epsilon_{Q, t}<0$, the largest suppliers will reduce trade following liberalization if $\epsilon_{p^{j}, Q}$ is sufficiently negative. Intuitively, while tariff cuts will have a positive direct effect on imports for the largest varieties (through the scaling of revenues by $\frac{1}{t}$ ), if aggregate quantity is a sufficiently strong substitute with each variety, the downward shift in demand for each variety due to the increase in competition will result in falling imports for the most successful varieties following liberalization.

Overall, the conditions in (25) and (26) are both satisfied when:

$$
\epsilon_{p^{j}, Q}<\min \left\{\frac{1}{\epsilon_{Q, t}}, \frac{P_{12}^{j}}{P_{1}^{j}} Q\right\}
$$

Note that if $P_{12}^{j} \leq 0$ then $\epsilon_{p^{j}, Q}<\frac{1}{\epsilon_{Q, t}}$ is more restrictive. Hence, (26) is the most restrictive condition when using quadratic preferences from Melitz and Ottaviano (2008), and any other demand function in which aggregate quantity has a weakly negative effect on the slope of inverse demand.

Summarizing the conditions from this Appendix, if (22) and (27) are both satisfied, then $\frac{\partial \epsilon_{v_{j}, t}}{\partial q_{j}}>$ 0 for all $q_{j}$, and $\epsilon_{v_{j}, t}>0$ for the most efficient suppliers.

\footnotetext{
${ }^{22}$ After imposing the FOC, $(25)$ is satisfied if $P_{12}^{j}<\underbrace{\left(\frac{c_{j} t}{P^{j}}-1\right)}_{\in(-1,0)} \frac{P_{2}^{j}}{q_{j}}$, where $(24)$ is satisfied if $P_{12}^{j}<-\frac{P_{2}^{j}}{q_{j}}$.
} 


\section{B Extensive Margin Derivations/Proofs}

\section{Tariffs and aggregate imports}

In this appendix, I derive the effects of tariffs on imports from exporter $l$ in product $s$. Recall that imports from $l$ in $s$ are written as:

$$
V_{l, s}^{H}=N_{l} L_{H} \int_{0}^{\frac{A_{H}-z_{H}}{t_{H}}} \frac{\left(A_{H}-z_{H}\right)^{2}-\left(c t_{H}\right)^{2}}{4 \gamma t_{H}} g_{l, s}(c) d c
$$

Taking logs, differentiating, and substituting the equation for $V_{l, s}^{H}$, we get:

$$
\frac{\partial V_{l, s}^{H}}{V_{l, s}^{H}}=\frac{\partial N_{l}}{N_{l}}-\frac{\partial t_{H}}{t_{H}}+\frac{N_{l} L_{H}}{4 \gamma t_{H} V_{l, s}} \cdot \int_{0}^{\frac{A_{H}-z_{H}}{t_{H}}}\left(2\left(A_{H}-z_{H}\right)\left(\partial A_{H}-\partial z_{H}\right)-2\left(c t_{H}\right)^{2} \frac{\partial t_{H}}{t_{H}}\right) g_{l, s}(c) d c
$$

Next, substituting for $\left(c t_{H}\right)^{2}$ using $v(c)=\frac{\left(A_{H}-z_{H}\right)^{2}-\left(c t_{H}\right)^{2}}{4 \gamma t_{H}}$, and simplifying, we get:

$$
\begin{aligned}
\frac{\partial V_{l, s}^{H}}{V_{l, s}^{H}}= & \frac{\partial N_{l}}{N_{l}}-\frac{\partial t_{H}}{t_{H}}+\frac{2 N_{l} L_{H}}{V_{l, s}} \cdot \int_{0}^{\frac{A_{H}-z_{H}}{t_{H}}} v(c) \frac{\partial t_{H}}{t_{H}} g_{l, s}(c) d c+ \\
& \frac{N_{l} L_{H}}{2 \gamma t_{H} V_{l, s}} \cdot \int_{0}^{\frac{A_{H}-z_{H}}{t_{H}}}\left(\left(A_{H}-z_{H}\right)\left(\partial A_{H}-\partial z_{H}\right)-\left(A_{H}-z_{H}\right)^{2} \frac{\partial t_{H}}{t_{H}}\right) g_{l, s}(c) d c
\end{aligned}
$$

Since $\int_{0}^{\frac{A_{H}-z_{H}}{{ }^{t} H}} v(c) g_{l, s}(c) d c=\frac{V_{l, s}^{H}}{N_{l} L_{H}}$, we can simplify $\frac{\partial V_{l, s}^{H}}{V_{l, s}^{H}}$ as follows:

$$
\frac{\partial V_{l, s}^{H}}{V_{l, s}^{H}}=\frac{\partial N_{l}}{N_{l}}+\frac{\partial t_{H}}{t_{H}}+\frac{N_{l} L_{H}}{2 \gamma t_{H} V_{l, s}} \cdot \int_{0}^{\frac{A_{H}-z_{H}}{t_{H}}}\left(\left(A_{H}-z_{H}\right)\left(\partial A_{H}-\partial z_{H}\right)-\left(A_{H}-z_{H}\right)^{2} \frac{\partial t_{H}}{t_{H}}\right) g_{l, s}(c) d c
$$

Finally, using the definition of $\bar{v}_{l, s}^{H}$ from $V_{l, s}^{H}=N_{l} G_{l, s}\left(\left(A_{H}-z_{H}\right) / t_{H}\right) \bar{v}_{l, s}^{H}$, and simplifying, we get the desired result:

$$
\frac{\partial V_{l, s}^{H}}{V_{l, s}^{H}}=\frac{\partial N_{l}}{N_{l}}+\frac{\partial t_{H}}{t_{H}}+\frac{\left(A_{H}-z_{H}\right) L_{H}}{2 \gamma t_{H} \bar{v}_{l, s}^{H}}\left(\partial A_{H}-\left(A_{H}-z_{H}\right) \frac{\partial t_{H}}{t_{H}}-\partial z_{H}\right)
$$

\section{Proposition 3}

To derive the short-run effects of trade shocks on $A_{H}$, recall that $A_{H}$ is pinned down by

$$
A_{H}=\theta-\eta\left(\sum_{s \in S} Q_{H, s}^{H}+\sum_{l \in M} \sum_{s \in S} Q_{l, s}^{H}\right)
$$


where,

$$
Q_{H, s}^{H}=N_{H} \int_{0}^{A_{H}} \frac{A_{H}-c}{2 \gamma} g_{H, s}(c) d c
$$

and

$$
Q_{l, s}^{H}=N_{l} \int_{0}^{\frac{A_{H}-z_{H}}{{ }^{t} H}} \frac{A_{H}-z_{H}-c \cdot t_{H}}{2 \gamma} g_{l, s}(c) d c
$$

Fully differentiating the equation for $A_{H}$, and collecting the $\partial A_{H}$ 's and trade shocks yields:

$$
\begin{aligned}
\partial A_{H}= & \underbrace{\frac{\eta \sum_{l \in M} \sum_{s \in S} N_{l} G_{l, s}\left(\frac{A_{H}-z_{H}}{t_{H}}\right) \bar{c}_{l, s}^{H} t_{H}}{\left(2 \gamma+\eta \sum_{s \in S} N_{H} G_{H, s}\left(A_{H}\right)+\eta \sum_{l \in M} \sum_{s \in S} N_{l} G_{l, s}\left(\frac{A_{H}-z_{H}}{t_{H}}\right)\right)}}_{\phi_{t} \in\left[0, A_{H}-z_{H}\right)} \frac{\partial t_{H}}{t_{H}} \\
& \underbrace{\frac{\left(2 \gamma+\eta \sum_{l \in M} \sum_{s \in S} N_{l} G_{l, s}\left(\frac{A_{H}-z_{H}}{t_{H}}\right)\right.}{\left(2 \gamma G_{H, s}\left(A_{H}\right)+\eta \sum_{l \in M} \sum_{s \in S} N_{l} G_{l, s}\left(\frac{A_{H}-z_{H}}{t_{H}}\right)\right)}}_{\phi_{z} \in[0,1)} \partial z_{H} \\
= & \phi_{t} \frac{\partial t_{H}}{t_{H}}+\phi_{z} \partial z_{H}
\end{aligned}
$$

where $\bar{c}_{l, s}^{H}$ is the average cost of firms from $l$, in $s$ that profitably export to $H$. Further, the upper bound on $\phi_{t}$ follows from the fact that $c t_{H}<A_{H}-z_{H}$ for all firms that profitably export. Plugging $\partial A_{H}$ into (10), we get:

$$
\begin{aligned}
\frac{\partial V_{l, s}^{H}}{V_{l, s}^{H}}= & \underbrace{\frac{\partial N_{l}}{N_{l}}}_{=}+\frac{\partial t_{H}}{t_{H}}-Y_{H} \overbrace{\frac{\left(A_{H}-z_{H}-\phi_{t}\right)}{\bar{v}_{l, s}^{H}}}^{>0} \frac{\partial t_{H}}{t_{H}}-Y_{H} \frac{\overbrace{\left(1-\phi_{z}\right)}^{\bar{v}_{l, s}^{H}}}{>0} \partial z_{H} \\
& \text { where } Y_{H}=\frac{\left(A_{H}-z_{H}\right) L_{H}}{2 \gamma t_{H}}
\end{aligned}
$$

Using the positive and monotone relationship between $\bar{v}_{l, s}^{H}$ and $V_{l, s}^{H}$ discussed on page 13 (when evaluated within exporter-industry pairs), in the short-run, within a given exporter-industry group, we have the result that tariff liberalization, whether specific or ad-valorem, increases imports to a larger degree from low-revenue $l, s$ pairs.

In the long run, it is clear from (12) that $A_{H}$ is pinned down by the free entry condition in $H$, within which tariffs play no (direct) role. Hence, $A_{H}$ is invariant to tariffs. Substituting $\partial A_{H}=0$ into (10) we get the result in Proposition 3. 
Table 1: Log Bilateral Import Value Growth and MFN Tariff Cuts - Within Exporter-Industry

\begin{tabular}{|c|c|c|c|c|c|c|c|}
\hline & (1) & (2) & (3) & (4) & $(5)$ & (6) & (7) \\
\hline $\log \left(v_{i, j}^{p r e}\right)$ & $\begin{array}{c}-0.225^{* * *} \\
(0.011)\end{array}$ & $\begin{array}{c}-0.219^{* * * *} \\
(0.006)\end{array}$ & $\begin{array}{c}-0.222^{* * *} \\
(0.011)\end{array}$ & $\begin{array}{c}-0.215^{* * *} \\
(0.012)\end{array}$ & $\begin{array}{c}-0.200^{* * *} \\
(0.014)\end{array}$ & $\begin{array}{c}-0.192^{* * *} \\
(0.015)\end{array}$ & $\begin{array}{c}-0.169^{* * *} \\
(0.016)\end{array}$ \\
\hline $\log \left(\frac{t_{i, 04}^{a v}}{t_{i, 92}^{a, v}}\right)$ & $\begin{array}{c}-2.107^{* * *} \\
(0.504)\end{array}$ & $\begin{array}{c}-7.313^{* * *} \\
(1.766)\end{array}$ & $\begin{array}{c}-2.388^{* * *} \\
(0.358)\end{array}$ & $\begin{array}{c}-8.066^{* * *} \\
(1.422)\end{array}$ & $\begin{array}{c}-1.787^{* *} \\
(0.752)\end{array}$ & $\begin{array}{c}-8.890^{* * *} \\
(2.551)\end{array}$ & \\
\hline $\log \left(\frac{t_{i, 04}^{a v}}{t_{i, 92}^{a v}}\right) \cdot \log \left(v_{i, j}^{p r e}\right)$ & & $\begin{array}{c}0.432^{* * *} \\
(0.139)\end{array}$ & & $\begin{array}{c}0.474^{* * *} \\
(0.124)\end{array}$ & & $\begin{array}{c}0.595^{* * *} \\
(0.197)\end{array}$ & $\begin{array}{c}1.160^{* * *} \\
(0.159)\end{array}$ \\
\hline$\Delta t_{i}^{\text {specific }}$ & $\begin{array}{l}-0.195 \\
(0.127)\end{array}$ & $\begin{array}{l}-0.443 \\
(0.744)\end{array}$ & $\begin{array}{l}-0.268^{*} \\
(0.161)\end{array}$ & $\begin{array}{l}-0.361 \\
(0.948)\end{array}$ & $\begin{array}{l}-0.129 \\
(0.179)\end{array}$ & $\begin{array}{l}-0.886 \\
(1.097)\end{array}$ & \\
\hline$\Delta t_{i}^{\text {specific }} \cdot \log \left(v_{i, j}^{\text {pre }}\right)$ & & $\begin{array}{l}0.017 \\
(0.058)\end{array}$ & & $\begin{array}{l}0.003 \\
(0.070)\end{array}$ & & $\begin{array}{l}0.057 \\
(0.081)\end{array}$ & $\begin{array}{l}0.186 \\
(0.213)\end{array}$ \\
\hline $\begin{array}{l}R^{2} \\
\text { Number of FEs }\end{array}$ & $\begin{array}{c}0.054 \\
\text { Exp-HS2 }\end{array}$ & $\begin{array}{c}0.054 \\
\text { Exp-HS2 }\end{array}$ & $\begin{array}{c}0.050 \\
\text { Exp-HS4 }\end{array}$ & $\begin{array}{c}0.050 \\
\text { Exp-HS4 }\end{array}$ & $\begin{array}{c}0.041 \\
\text { Exp-HS6 }\end{array}$ & $\begin{array}{c}0.042 \\
\text { Exp-HS6 }\end{array}$ & $\begin{array}{c}0.037 \\
\text { Exp-HS8 }\end{array}$ \\
\hline
\end{tabular}

Notes: The above table reports the estimates from regressing import growth between 1992 and 2004 on $\log$ tariff changes, log initial imports in 1989-1990, and an interaction between the two. The unit of observation is ExporterHS10. The total sample includes 54,149 observations. Fixed Effects are included according to the row "Fixed". Robust standard errors, clustered at the Exporter and HS2 level (via the multi-level procedure in Cameron, Gelbach, and Miller (2011)), in parentheses.*** $\mathrm{p}<0.01,{ }^{* *} \mathrm{p}<0.05,{ }^{*} \mathrm{p}<0.1$ 
Table 2: Log Bilateral Import Value Growth and MFN Tariff Cuts - Within Industry

\begin{tabular}{|c|c|c|c|c|c|c|c|}
\hline & (1) & $(2)$ & (3) & (4) & $(5)$ & (6) & (7) \\
\hline $\log \left(v_{i, j}^{p r e}\right)$ & $\begin{array}{c}-0.212^{* * *} \\
(0.016)\end{array}$ & $\begin{array}{c}-0.204^{* * *} \\
(0.016)\end{array}$ & $\begin{array}{c}-0.212^{* * *} \\
(0.016)\end{array}$ & $\begin{array}{c}-0.206^{* * *} \\
(0.016)\end{array}$ & $\begin{array}{c}-0.213^{* * *} \\
(0.016)\end{array}$ & $\begin{array}{c}-0.206^{* * *} \\
(0.017)\end{array}$ & $\begin{array}{c}-0.205^{* * *} \\
(0.016)\end{array}$ \\
\hline $\log \left(\frac{t_{i, 04}^{a v}}{t_{i, 92}^{a, v}}\right)$ & $\begin{array}{c}-2.035 * * * \\
(0.469)\end{array}$ & $\begin{array}{c}-8.486 * * * \\
(2.467)\end{array}$ & $\begin{array}{c}-2.777^{* * *} \\
(0.223)\end{array}$ & $\begin{array}{c}-8.085^{* * *} \\
(2.132)\end{array}$ & $\begin{array}{c}-2.167^{* * *} \\
(0.678)\end{array}$ & $\begin{array}{c}-8.087^{* * *} \\
(2.412)\end{array}$ & \\
\hline $\log \left(\frac{t_{i, 04}^{a v}}{t_{i, 92}^{a v}}\right) \cdot \log \left(v_{i, j}^{p r e}\right)$ & & $\begin{array}{c}0.534^{* * *} \\
(0.200)\end{array}$ & & $\begin{array}{c}0.446^{* *} \\
(0.181)\end{array}$ & & $\begin{array}{c}0.506^{* * *} \\
(0.184)\end{array}$ & $\begin{array}{c}0.532^{* * *} \\
(0.182)\end{array}$ \\
\hline$\Delta t_{i}^{\text {specific }}$ & $\begin{array}{l}-0.112 \\
(0.141)\end{array}$ & $\begin{array}{l}-0.581 \\
(0.864)\end{array}$ & $\begin{array}{l}-0.157 \\
(0.189)\end{array}$ & $\begin{array}{l}-0.467 \\
(0.804)\end{array}$ & $\begin{array}{l}-0.090 \\
(0.224)\end{array}$ & $\begin{array}{l}-0.100 \\
(0.845)\end{array}$ & \\
\hline$\Delta t_{i}^{\text {specific }} \cdot \log \left(v_{i, j}^{p r e}\right)$ & & $\begin{array}{l}0.035 \\
(0.068)\end{array}$ & & $\begin{array}{l}0.022 \\
(0.059)\end{array}$ & & $\begin{array}{l}-0.003 \\
(0.061)\end{array}$ & $\begin{array}{l}-0.045 \\
(0.065)\end{array}$ \\
\hline $\begin{array}{l}R^{2} \\
\text { Fixed }\end{array}$ & $\begin{array}{c}0.053 \\
\text { HS2 }\end{array}$ & $\begin{array}{c}0.054 \\
\text { HS2 }\end{array}$ & $\begin{array}{c}0.052 \\
\text { HS4 }\end{array}$ & $\begin{array}{c}0.052 \\
\text { HS4 }\end{array}$ & $\begin{array}{c}0.051 \\
\text { HS6 }\end{array}$ & $\begin{array}{c}0.051 \\
\text { HS6 }\end{array}$ & $\begin{array}{c}0.050 \\
\text { HS8 }\end{array}$ \\
\hline
\end{tabular}

Notes: The above table reports the estimates from regressing import growth between 1992 and 2004 on $\log$ tariff changes, log of initial imports in 1989-1990, and an interaction between the two. The unit of observation is ExporterHS10. The total sample includes 54,149 observations. Fixed Effects are included according to the row "Fixed". Robust standard errors, clustered at the Exporter and HS2 level (via the multi-level procedure in Cameron, Gelbach, and Miller (2011)), in parentheses. ${ }^{* * *} \mathrm{p}<0.01,{ }^{* *} \mathrm{p}<0.05,{ }^{*} \mathrm{p}<0.1$ 
Table 3: Percent Import Value Growth and MFN Tariff Cuts - Within Exporter-Industry

\begin{tabular}{lccccccc}
\hline \hline & $(1)$ & $(2)$ & $(3)$ & $(4)$ & $(5)$ & $(6)$ & $(7)$ \\
\hline & & & & & & & \\
$v_{i, j}^{\text {pre }}$ & $-0.001^{*}$ & $-0.001^{*}$ & $-0.002^{*}$ & $-0.001^{*}$ & $-0.002^{*}$ & $-0.002^{*}$ & $-0.002^{*}$ \\
& $(0.001)$ & $(0.001)$ & $(0.001)$ & $(0.001)$ & $(0.001)$ & $(0.001)$ & $(0.001)$ \\
$\% \Delta t_{04,92}$ & $-1.319^{* * *}$ & $-1.475^{* * *}$ & $-1.199^{* * *}$ & $-1.318^{* * *}$ & $-0.538^{*}$ & $-0.643^{* *}$ & \\
$\% \Delta t_{04,92} \cdot v_{i, j}^{\text {pre }}$ & $(0.395)$ & $(0.413)$ & $(0.282)$ & $(0.299)$ & $(0.299)$ & $(0.299)$ & \\
& & $0.173^{* * *}$ & & $0.144^{* * *}$ & & $0.161^{* * *}$ & $0.182^{* * *}$ \\
$\Delta t_{i}^{\text {specific }}$ & & $(0.056)$ & & $(0.044)$ & & $(0.055)$ & $(0.069)$ \\
& $-0.219^{* *}$ & $-0.249^{* *}$ & $-0.302^{* *}$ & $-0.330^{* *}$ & -0.123 & -0.149 & \\
$\Delta t_{i}^{\text {specific }} \cdot v_{i, j}^{\text {pre }}$ & $(0.107)$ & $(0.116)$ & $(0.124)$ & $(0.130)$ & $(0.155)$ & $(0.161)$ & \\
& & 0.028 & & 0.021 & & 0.027 & $0.210^{* * *}$ \\
& & $(0.021)$ & & $(0.018)$ & & $(0.026)$ & $(0.044)$ \\
$R^{2}$ & & & & & & & \\
Fixed & 0.002 & 0.002 & 0.001 & 0.002 & 0.002 & 0.002 & 0.003 \\
& Exp-HS2 & Exp-HS2 & Exp-HS4 & Exp-HS4 & Exp-HS6 & Exp-HS6 & Exp-HS 8 \\
\hline
\end{tabular}

Notes: The above table reports the estimates from regressing percent import growth between 1992 and 2004 on percent tariff changes, initial imports in 1989-1990 (in millions of \$US), and an interaction between the two. Percent growth is calculated using the mid-point formula. The unit of observation is Exporter-HS10. The total sample includes 161,799 observations. Fixed Effects are included according to the row "Fixed". Robust standard errors, clustered at the Exporter and HS2 level (via the multi-level procedure in Cameron, Gelbach, and Miller (2011)), in parentheses. $^{* * *} \mathrm{p}<0.01,{ }^{* *} \mathrm{p}<0.05,{ }^{*} \mathrm{p}<0.1$ 
Table 4: Aggregation Bias and Large Supplier Elasticities

\begin{tabular}{cccc} 
Aggregation Bias & Exporter-HS2 & Exporter-HS4 & Exporter-HS6 \\
\hline Naive Elasticity & -2.107 & -2.388 & -1.787 \\
Average True Elasticity & -1.373 & -1.488 & -0.734 \\
Medan True Elasticity & -1.315 & -1.440 & -0.704 \\
& & & \\
Large Exporter Elasticities & Exporter-HS2 & Exporter-HS4 & Exporter-HS6 \\
\hline Full Sample & & & \\
90th percentile & -0.568 & -0.663 & 0.404 \\
& $(0.615)$ & $(0.634)$ & $(0.885)$ \\
95th percentile & -0.214 & -0.275 & 0.891 \\
& $(0.671)$ & $(0.724)$ & $(1.001)$ \\
99th percentile & 0.420 & 0.421 & 1.766 \\
& $(0.788)$ & $(0.891)$ & $(1.235)$ \\
\hline High $\sigma$ Products & & & \\
& - & 0.393 & $1.603^{* *}$ \\
& - & $(0.292)$ & $(0.693)$ \\
& - & $1.005^{* * *}$ & $2.311^{* * *}$ \\
& - & $(0.353)$ & $(0.801)$ \\
& - & $2.102^{* * *}$ & $3.581^{* * *}$ \\
& - & $(0.486)$ & $(1.035)$ \\
\hline
\end{tabular}

Notes: The above table reports various measures of bias in assuming that tariff elasticities are constant across suppliers. In the top panel, I measure the naively estimated constant elasticity against the average and median true elasticity at the exporter-industry level as calculated in equation (14). Averages and medians are calculated across all exporter-industry groups for which there is more than one observation within each group. The middle and bottom panels report the estimated Exporter-HS10 elasticities for the 90th, 95th, and 99th percentiles of total import value in 1989 and 1990. The bottom panel provides estimated Exporter-HS10 elasticities for the 90th, 95th, and 99th percentiles for observations within high elasticity of substitution HS8 products. 
Table 5: Log Bilateral Trade Growth and MFN Tariff Cuts - BW $\sigma$

$(1)$

Low $\sigma$ HS8 Products

$$
\begin{array}{rccc}
\log \left(v_{i, j}^{\text {pre }}\right) & -0.235^{* * *} & -0.226^{* * *} & -0.194^{* * *} \\
& (0.011) & (0.018) & (0.033) \\
\log \left(\frac{t_{i, 04}^{a v}}{t_{i, 92}^{a v}}\right) & 0.476 & 1.728 & \\
& (3.262) & (4.068) & \\
\log \left(\frac{t_{i, 04}^{a v}}{t_{i, 92}^{a v}}\right) \cdot \log \left(v_{i, j}^{\text {pre }}\right) & -0.286 & -0.367 & -0.178 \\
& (0.222) & (0.316) & (0.940) \\
\Delta t_{i}^{\text {specific }} & 1.439 & 1.658 & \\
\Delta t_{i}^{\text {specific }} \cdot \log \left(v_{i, j}^{\text {pre }}\right) & (1.481) & (2.160) & \\
& -0.158 & -0.166 & -0.068 \\
& (0.119) & (0.167) & (0.752)
\end{array}
$$

High $\sigma$ HS8 Products

$$
\begin{array}{rccc}
\log \left(v_{i, j}^{\text {pre }}\right) & -0.209^{* * *} & -0.179^{* * *} & -0.166^{* * *} \\
& (0.015) & (0.018) & (0.018) \\
\log \left(\frac{t_{i, 04}^{a v}}{t_{i, 92}^{a v}}\right) & -10.906^{* * *} & -11.481^{* * *} & \\
& (1.599) & (2.913) & \\
\log \left(\frac{t_{i, 04}^{a v}}{t_{i, 92}^{a v}}\right) \cdot \log \left(v_{i, j}^{\text {pre }}\right) & 0.719^{* * *} & 0.833^{* * *} & 1.352^{* * *} \\
& (0.110) & (0.204) & (0.246) \\
\Delta t_{i}^{\text {specific }} & -1.248 & -1.932 & \\
& (1.504) & (2.212) & \\
\Delta t_{i}^{\text {specific }} \cdot \log \left(v_{i, j}^{\text {pre }}\right) & 0.084 & 0.156 & 0.230 \\
& (0.114) & (0.164) & (0.236) \\
R^{2} & 0.051 & 0.043 & 0.037 \\
\text { FEs } & \text { Exp-HS4 } & \text { Exp-HS6 } & \text { Exp-HS8 } \\
\hline & & &
\end{array}
$$

Notes: The above table reports the estimates from regressing import growth between 1992 and 2004 on tariff changes, initial imports in 1989-1990, and an interaction between the two for different HS8 Groups. Separate coefficients are estimated depending on whether the HS8 group has an estimated elasticity of substitution above or below median. Low-high substitution dummies are omitted for clarity. Elasticity of substitution estimates are obtained from Broda and Weinstein (2006). The unit of observation is Exporter-HS10. The total sample includes 54,149 observations. Fixed Effects are included according to the row "Fixed". Robust standard errors, clustered at the Exporter and HS2 level (via the multi-level procedure in Cameron, Gelbach, and Miller (2011)), in parentheses.*** $\mathrm{p}<0.01,{ }^{* *} \mathrm{p}<0.05$, $* \mathrm{p}<0.1$ 
Table 6: Log Bilateral Trade Growth and MFN Tariff Cuts - Exporter Concentration

\begin{tabular}{|c|c|c|c|}
\hline & (1) & $(2)$ & $(3)$ \\
\hline \multicolumn{4}{|c|}{ Low HS8 Exporter Concentration } \\
\hline $\log \left(v_{i, j}^{p r e}\right)$ & $\begin{array}{c}-0.216^{* * *} \\
(0.012)\end{array}$ & $\begin{array}{c}-0.187^{* * *} \\
(0.015)\end{array}$ & $\begin{array}{c}-0.168 * * * \\
(0.016)\end{array}$ \\
\hline $\log \left(\frac{t_{i, 04}^{a v}}{t_{i, 92}^{a v}}\right)$ & $\begin{array}{c}-9.890 * * * \\
(0.944)\end{array}$ & $\begin{array}{c}-10.593^{* * *} \\
(2.511)\end{array}$ & \\
\hline $\log \left(\frac{t_{i, 04}^{a v}}{t_{i, 92}^{a v}}\right) \cdot \log \left(v_{i, j}^{p r e}\right)$ & $\begin{array}{c}0.605^{* * *} \\
(0.067)\end{array}$ & $\begin{array}{c}0.739 * * * \\
(0.182)\end{array}$ & $\begin{array}{c}1.196^{* * *} \\
(0.166)\end{array}$ \\
\hline$\Delta t_{i}^{\text {specific }}$ & $\begin{array}{l}0.733 \\
(0.786)\end{array}$ & $\begin{array}{l}-0.699 \\
(1.354)\end{array}$ & \\
\hline$\Delta t_{i}^{\text {specific }} \cdot \log \left(v_{i, j}^{\text {pre }}\right)$ & $\begin{array}{l}-0.087 \\
(0.068)\end{array}$ & $\begin{array}{l}0.065 \\
(0.126)\end{array}$ & $\begin{array}{c}0.379 * * * \\
(0.073)\end{array}$ \\
\hline
\end{tabular}

High HS8 Exporter Concentration

\begin{tabular}{rccc}
$\log \left(v_{i, j}^{\text {pre }}\right)$ & $-0.233^{* * *}$ & $-0.250^{* * *}$ & $-0.227^{* * *}$ \\
& $(0.015)$ & $(0.018)$ & $(0.047)$ \\
$\log \left(\frac{t_{i, 04}^{a v}}{t_{i, 92}^{a v}}\right)$ & -0.766 & -0.990 & \\
& $(4.062)$ & $(5.161)$ & \\
$\log \left(\frac{t_{i, 04}^{a v}}{t_{i, 92}^{a v}}\right) \cdot \log \left(v_{i, j}^{\text {pre }}\right)$ & -0.079 & -0.094 & -2.806 \\
& $(0.328)$ & $(0.459)$ & $(2.200)$ \\
$\Delta t_{i}^{\text {specific }}$ & -0.538 & -0.016 & \\
& $(1.352)$ & $(1.822)$ & \\
$\Delta t_{i}^{\text {specific }} \cdot \log \left(v_{i, j}^{\text {pre }}\right)$ & 0.013 & -0.023 & $-2.319 * * *$ \\
& $(0.100)$ & $(0.132)$ & $(0.835)$ \\
$R^{2}$ & 0.052 & 0.044 & 0.037 \\
Fixed & Exp-HS4 & Exp-HS6 & Exp-HS8 \\
\hline
\end{tabular}

Notes: The above table reports the estimates from regressing import growth between 1992 and 2004 on tariff changes, initial imports in 1989-1990, and an interaction between the two for different HS8 Groups. Separate coefficients are estimated depending on whether the HS8 group has a calculated level of exporter concentration above or below the sample median. Exporter concentration is calculated at the HS8 level using a Hirschman-Herfindahl index. Exporter concentration dummies are omitted for clarity. The unit of observation is Exporter-HS10. The total sample includes 54,149 observations. Fixed Effects are included according to the row "Fixed". Robust standard errors, clustered at the Exporter and HS2 level (via the multi-level procedure in Cameron, Gelbach, and Miller (2011)), in parentheses.*** $\mathrm{p}<0.01,{ }^{* *} \mathrm{p}<0.05,{ }^{*} \mathrm{p}<0.1$ 
Table 7: Log Bilateral Import Value Growth and Exchange Rates

\begin{tabular}{|c|c|c|c|c|c|c|}
\hline & (1) & $(2)$ & $(3)$ & $(4)$ & $(5)$ & (6) \\
\hline $\log \left(v_{i, j}^{p r e}\right)$ & $\begin{array}{c}-0.203^{* * *} \\
(0.017)\end{array}$ & $\begin{array}{c}-0.179^{* * *} \\
(0.023)\end{array}$ & $\begin{array}{c}-0.141^{* * *} \\
(0.027)\end{array}$ & $\begin{array}{c}-0.213^{* * *} \\
(0.011)\end{array}$ & $\begin{array}{c}-0.186^{* * *} \\
(0.014)\end{array}$ & $\begin{array}{c}-0.160 * * * \\
(0.014)\end{array}$ \\
\hline $\log \left(\frac{t_{i, 04}^{a v}}{t_{i, 92}^{a v}}\right)$ & & & & $\begin{array}{c}-8.139^{* * *} \\
(1.403)\end{array}$ & $\begin{array}{c}-8.932^{* * *} \\
(2.528)\end{array}$ & \\
\hline $\log \left(\frac{t_{i, 04}^{a v}}{t_{i, 92}^{a v}}\right) \cdot \log \left(v_{i, j}^{p r e}\right)$ & & & & $\begin{array}{c}0.479^{* * *} \\
(0.122)\end{array}$ & $\begin{array}{c}0.598^{* * *} \\
(0.195)\end{array}$ & $\begin{array}{c}1.167^{* * * *} \\
(0.154)\end{array}$ \\
\hline$\Delta t_{i}^{\text {specific }}$ & & & & $\begin{array}{l}-0.383 \\
(0.950)\end{array}$ & $\begin{array}{l}-0.949 \\
(1.091)\end{array}$ & \\
\hline$\Delta t_{i}^{\text {specific }} \cdot \log \left(v_{i, j}^{\text {pre }}\right)$ & & & & $\begin{array}{l}0.005 \\
(0.070)\end{array}$ & $\begin{array}{l}0.061 \\
(0.080)\end{array}$ & $\begin{array}{l}0.203 \\
(0.207)\end{array}$ \\
\hline $\log \left(\frac{x_{i, 04}}{x_{i, 92}}\right) \cdot \log \left(v_{i, j}^{p r e}\right)$ & $\begin{array}{c}-0.013^{* * *} \\
(0.003)\end{array}$ & $\begin{array}{c}-0.048^{* * *} \\
(0.006)\end{array}$ & $\begin{array}{c}-0.065^{* * *} \\
(0.012)\end{array}$ & $\begin{array}{c}-0.007^{*} \\
(0.004)\end{array}$ & $\begin{array}{c}-0.016^{* * *} \\
(0.006)\end{array}$ & $\begin{array}{c}-0.022^{* * *} \\
(0.005)\end{array}$ \\
\hline $\begin{array}{l}R^{2} \\
\text { Fixed }\end{array}$ & $\begin{array}{c}0.044 \\
\text { Exp-HS4 }\end{array}$ & $\begin{array}{c}0.041 \\
\text { Exp-HS6 }\end{array}$ & $\begin{array}{c}0.034 \\
\text { Exp-HS8 }\end{array}$ & $\begin{array}{c}0.050 \\
\text { Exp-HS4 }\end{array}$ & $\begin{array}{c}0.042 \\
\text { Exp-HS6 }\end{array}$ & $\begin{array}{c}0.037 \\
\text { Exp-HS8 }\end{array}$ \\
\hline
\end{tabular}

Notes: The above table reports the estimates from regressing import growth between 1992 and 2004 on trade shocks (exchange rates, ad-valorem tariffs, and specific tariffs), initial imports in 1989-1990, and an interaction between the two. The left three columns report regressions with no movement in tariffs (ad-valorem or specific). The right three columns use the full sample with all trade shocks. The unit of observation is Exporter-HS10. The total sample includes 54,149 observations. Fixed Effects are included according to the row "Fixed". Robust standard errors, clustered at the Exporter and HS2 level (via the multi-level procedure in Cameron, Gelbach, and Miller (2011)), in parentheses. $^{* * *} \mathrm{p}<0.01,{ }^{* *} \mathrm{p}<0.05,{ }^{*} \mathrm{p}<0.1$ 